\title{
QUANTIFYING THE GREENHOUSE GAS EMISSIONS OF HAZARDS: INCORPORATING DISASTER MITIGATION STRATEGIES INTO CLIMATE ACTION PLANS
}

\author{
A Thesis \\ presented to \\ the Faculty of California Polytechnic State University, \\ San Luis Obispo
}

\author{
In Partial Fulfillment \\ of the Requirements for the Degree \\ Master of City and Regional Planning
}

by

Michael Germeraad

March 2014 
(C) 2014

Michael Germeraad

ALL RIGHTS RESERVED

Page ii 
COMMITTEE MEMBERSHIP

TITLE:

AUTHOR:

DATE SUBMITTED:

COMMITTEE CHAIR:

COMMITTEE MEMBER:

COMMITTEE MEMBER:

COMMITTEE MEMBER:
Quantifying the Greenhouse Gas Emissions of Hazards: Incorporating Disaster Mitigation Strategies into Climate Action Plans

Michael Germeraad

March 2014

Dr. William Siembieda, Professor City \& Regional Planning Department

Dr. Michael Boswell, Professor

City \& Regional Planning Department

Arrietta Chakos, MPP, Principal

Urban Resilience Strategies

Dana Brechwald, MUP, Earthquake \& Hazards Specialist

Association of Bay Area Governments 


\begin{abstract}
Quantifying the Greenhouse Gas Emissions of Hazards: Incorporating Disaster Mitigation Strategies into Climate Action Plans
\end{abstract}

\begin{abstract}
Michael Germeraad
Reconstruction after natural disasters can represent large peaks in a community's greenhouse gas emission inventory. Components of the built environment destroyed by natural hazards have their useful life shortened, requiring replacement before functionally necessary. Though the hazard itself does not release greenhouse gasses, the demolition and rebuilding process does, and these are the emissions we can quantify to better understand the climate impacts of disasters.

The proposed methodology draws data from existing emission and hazard resource literature and combines the information in a community scale life cycle assessment. Case studies of past disasters are used to refine the methodology and quantify the emissions of single events. The methodology is then annualized projecting the emissions of future hazards. The annualization of greenhouse gasses caused by hazard events provides a baseline from which reduction strategies can be measured against. Hazard mitigation strategies can then be quantified as greenhouse gas reduction strategies for use in Climate Action Plans.

The methodology combines the fields of climate action, hazard mitigation, and climate adaptation. Each field attempts to create sustainable and resilient communities, but most plans silo each discipline, missing opportunities that are mutually beneficial. Quantifying the greenhouse gasses associated with recovery following a disaster blends these fields to allow development of comprehensive resilience and sustainability strategies that lower greenhouse gases and decrease risk from existing or projected hazards.
\end{abstract}

An online supplement to this thesis is available online at disasterghg.wordpress.com

Keywords: Resilience, Disasters, Planning, Climate Action, Hazard Mitigation, Climate Adaptation. 


\section{ACKNOWLEDGMENTS}

This thesis blends a number of disciplines and I am fortunate to have members on my committee who are experts in multiple fields. Together they formed an invaluable resource of diverse expertise to tap when framing the research. A special thanks to Dr. Siembieda for his patience when I was indecisive between thesis topics. His comprehensive knowledge of hazards and disaster recovery aided the directions of the research. I appreciate the entire committees work (Dr. Siembieda, Dr. Boswell, Arrietta Chakos, and Dana Brechwald) in the final months with their keen and responsive review of the work. I hope to stay connected and work with the committee on issues addressed in this research.

In addition to my committee this thesis leans heavily on others research. The detailed documentation of past disasters and the collection of life cycle analysis studies are the foundation of this research. Without their work there would be nothing to expand upon. In particular the following researchers work was a necessary piece for this thesis: Dr. Comerio, Dr. Ramaswami, Dr. Ramesh, Dr. Hammond, and Dr. Dixit.

Lastly, I have to thank my friends and family. My colleagues at Cal Poly have been a resource of technical knowledge, but more importantly friendship. I am so blessed to have the family I have as they have been supportive of my education for the past 25 years.

Thank you all so much, I'm lucky to be surrounded by such innovative and supportive individuals. 


\section{TABLE OF CONTENTS}

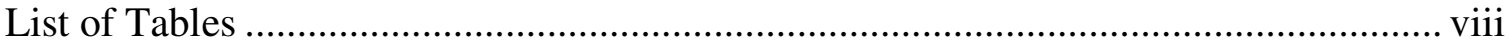

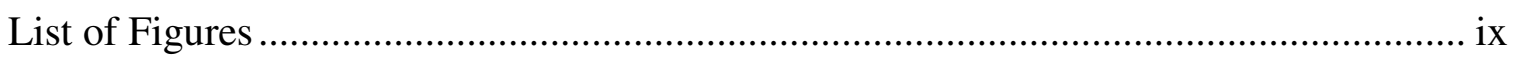

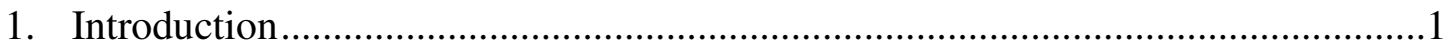

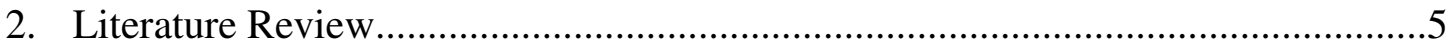

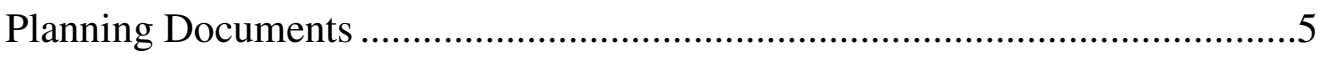

Climate Action Planning .........................................................................

Hazards Planning: LHMPs and Climate Adaptation Plans......................

Life Cycle Assessments ..............................................................................

Economic Input Output LCA Method ......................................................13

Process Based LCA Method ...................................................................14

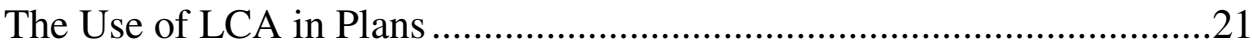

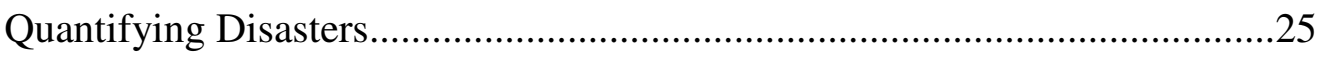

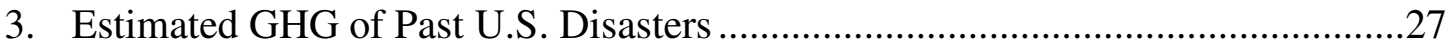

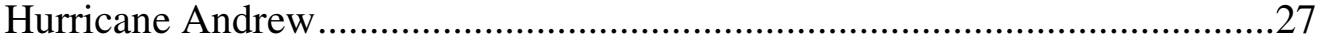

Comparison of Methodology Results ........................................................32

Northridge Earthquake ..................................................................................

4. Including Disaster Produced GHGs in CAP Inventories .........................................36

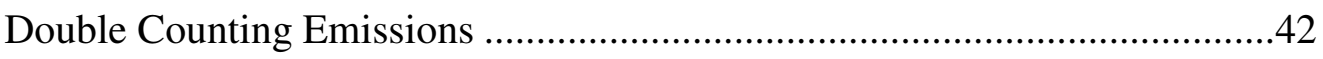

5. Greenhouse Gas Reduction Strategies ………………....................................48

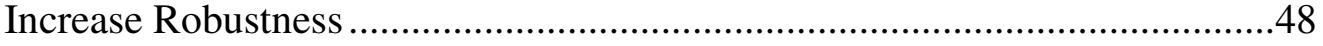

Building Code .....................................................................................49

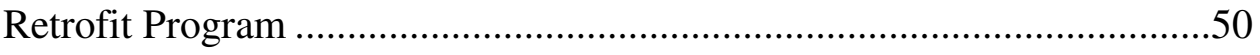

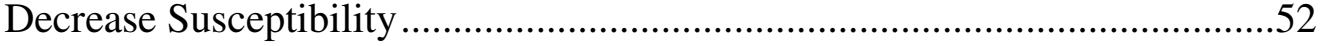

Land Use Hazard Overlay .......................................................................53

Engineered Infrastructure........................................................................53

Other Reduction Strategies, Resilience Strategies............................................55 


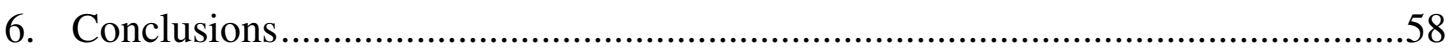

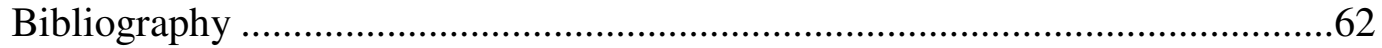

Appendix A: FEMA's Preliminary Damage Assessment Methodology ..............66

Appendix B: Process Based LCA Database Table .............................................67

Appendix C: CGS Annualized Building Loss Assessment ...............................69 


\section{LIST OF TABLES}

Table

Page

1. LCA Emissions of an Office Building

2. Statistical Breakdown of 73 Residential Structure PB LCAs $\left(\mathrm{kgCO}_{2} \mathrm{e} / \mathrm{m}^{2}\right)$

3. Statistical Breakdown of 35 Commercial Structure PB LCAs

$$
\left(\mathrm{kgCO}_{2} \mathrm{e} / \mathrm{m}^{2}\right) \text {. }
$$

4. Comparison of Two Bay Area Cities per Capita Emissions......................22

5. Comparison of Two Bay Area Cities, Percent Emissions by Sector

6. Hurricane Andrew Damage and EIO GHG Estimate .29

7. Hurricane Andrew Damage to GHG Estimate (Process Based) .................30

8. List of Variables used for Process Based Estimate.................................... 31

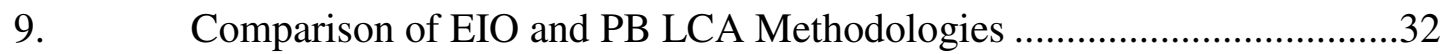

10. Northridge Earthquake Damage and EIO GHG Estimate ........................35

11. Annualized Earthquake Hazard Emissions .............................................41

12. Breakdown of Construction Phase Emissions of an Office Building ........44

13. Embodied Emission Breakdown of an Office Building ..........................45

14. Embodied Emission Breakdown of a Single Family Home .....................45 


\section{LIST OF FIGURES}

Figure Page

1. Increase in Climate Action Plan adoption over the past decade ..................5

2. Adopted LHMPs across the United States in 2012 .................................8

3. Life Cycle Assessment Phases. Some designations consider cradle to gate as just the first two phases. In this study cradle to gate is the first three........................................................................... 10

4. Embodied emissions are a greater share of overall life cycle emissions of energy efficient structures............................................12

5. Square Footage of U.S. Single Family Home (1970-2010).....................16

6. Distribution of U.S. Apartment Floor Areas (1978 \& 2007) .....................16

7. Histogram of $\mathrm{kgCO}_{2} \mathrm{e} / \mathrm{m}^{2}$ for 73 Residential Structure LCAs ..................19

8. Histogram of $\mathrm{kgCO}_{2} \mathrm{e} / \mathrm{m}^{2}$ for 35 Commercial Structure LCAs. ...............21

9. 2005 Denver emissions using the hybrid methodology ...........................24

10. Variables used to calculate the annualized building vulnerability..............38

11. Annualized Percent Loss of Buildings in San Francisco, Oakland, Alameda, and Berkeley

12. Theoretical impact of a building code or retrofit program on a building fragility curve

13. Impact of reduction strategy on the annual probability of hazard occurrence 


\section{CHAPTER 1}

Introduction

A suite of planning documents guide how cities and regions develop. Individual planning documents often focus on a single issue, but the impacts often affect other disciplines. Some plans do a good job of recognizing the range of impacts while others miss opportunities to extend benefits beyond their main goal. Since 2000 a number of new local planning guides have been adopted to address both sustainability and hazards. Climate Action Plans, Climate Adaptation Plans, and Local Hazard Mitigation Plans are each specifically addressing issues of climate change or hazards.

Many communities have recognized the link between planning and emissions. The decision on how land use is organized and how cityscapes are designed has a large impact on a community's emissions. Climate Action Plans (CAP's) inventory a community's emissions, often just from transportation and building energy use, and then propose reduction strategies to lower emissions in the future. Most adopted plans suggest engineered solutions including LED lighting replacements, low emission vehicles, and other replacement programs, while more aggressive strategies try to decrease vehicle miles traveled by diversifying housing, or improving bike and pedestrian infrastructure. The goal of these plans is to measure the existing emissions of a jurisdiction and then reduce emissions to meet a target.

Most science suggests that regardless of how well we lower our emissions in the future, the climate will continue to warm and climate change impacts will occur (Hamilton, 2010). Knowing these changes are inevitable, many communities have begun drafting 
climate adaptation plans. A number of major US cities began addressing adaptation with planning policies in 2007 (Poyar \& Beller-Simms, 2010). The plans typically quantify the range of potential future impacts (height of the sea level, temperature, storm intensity) and then suggest adaptation strategies to lessen the impacts of these forces on a community. Coastal communities are among the early adopters of adaptation plans, often specifically focusing on sea level rise.

Natural hazards are often repetitive events that can be predicted and mapped with some level of certainty. Local Hazard Mitigation Plans recognize past patterns and study the hazard forces providing communities with an opportunity to plan for future hazards. Most hazard mitigation plans map and quantify the hazard potential and then develop mitigation strategies for high risk zones to limit future losses.

The three plans all follow a similar format; they inventory as best they can the current condition, and then propose methods to reduce future impacts (GHG or damage). There are links between each of these plans. Adaptation plans and hazard mitigation plans are nearly identical with adaptation plans simply projecting future hazard levels rather than using historic patterns. Adaptation plans and CAPs are both focused around climate change. Despite the similar ground, there are concerns in the climate change community that GHG reduction is being left behind as emphasis moves to adaptation and the attempt to slow/stop climate change will be abandoned to adapt to the changes instead. This is a realistic concern as planning and implementation have limited funding. Linking hazard mitigation as a GHG reduction strategy however compliments the objective of both, building greater support for projects. There are a number of strategies that can 
simultaneously attain the goals of CAPs, LHMPs, and adaptation plans by 1) averting future GHG, 2) reducing risk, and in the case of climate related hazards, 3) reducing future hazard forces. The linkage is stronger for communities at risk of sea level rise, hurricanes, fire, or any hazard that increases severity with climate change. The process is still beneficial for earthquake mitigation, a hazard that is not expected to change due to climate change; GHG reduction just will not decrease the future earthquake hazard. Including hazard mitigation as a reduction strategy for GHG's will simultaneously reduce future GHGs and damage in future events.

Blending the hazards and climate change fields and planning documents could improve the missions of both. The climate change and natural hazards communities are converging. Climate change advocates recognize that future impacts are inevitable with hazard events becoming greater and more frequent, and likewise the hazards community recognizes that if drastic greenhouse gas reduction measures are not adopted, many hazards will rise. Both fields have been trying to reduce losses to make communities resilient. Blending the two fields has the potential to build support across two fields, and generate new funding for projects that reduce greenhouse gasses, decrease disaster losses, and in turn lower the future hazard risks and make communities more resilient. Developing a methodology to link the hazards and greenhouse gas emissions is necessary so that planners are not comparing apples and oranges. A method that addresses both hazards and greenhouse gasses can help build a common language among both fields, leverage cross cutting knowledge from both fields, and focus funding on projects that address resilience holistically. 
Most greenhouse gas emission inventories measure the emissions from tail pipes and building electrical use, but few inventories measure emissions used to mine and manufacture the cars and buildings. Life Cycle Assessment (LCA) is a method of quantifying the emissions over the life of a product, sometimes referred to as a product carbon footprint. Reducing the production of products can greatly reduce emissions. The same argument for the use of reusable water bottles versus disposable water bottles applies to buildings; the replacement frequency should be minimized. Natural Disasters shorten the life span of buildings and contents resulting in large amounts of debris requiring an equal amount of resources and their embodied GHGs to rebuild. This thesis takes past disaster damage counts and using LCAs quantifies the emissions required to replace and rebuild.

Results from the proposed methodology suggest emissions from disaster losses represent a measureable portion of a community's annualized emissions in high hazard regions. The methodology uses life cycle calculations of products and future damage projections, both of which have a high level of uncertainty. Despite potential for large uncertainty the method recognizes links that do exist and provides a metric for measuring baseline conditions against mitigated futures. Including hazard related emissions in Climate Action Plans offers an opportunity to tie hazard mitigation with greenhouse gas reduction strategies. These reduction strategies will instill a negative feedback loop where the reduction strategy prevents future disaster losses, which in turn lowers the future hazard risk, making communities more resilient. 


\section{CHAPTER 2}

Literature Review

Planning Documents

\section{Climate Action Planning}

Climate Action Plans (CAPs) have become increasingly used by cities and counties to address climate change at the local level. The voluntary plans inventory a jurisdiction's existing greenhouse gas (GHG) emissions, and then set a target to be reached by a variety of GHG reduction strategies. These plans are dictating bold decisions which will change transportation schemes and land use patterns for cities. Over the past few years the adoption rate by cities has increased dramatically; see Figure 1.

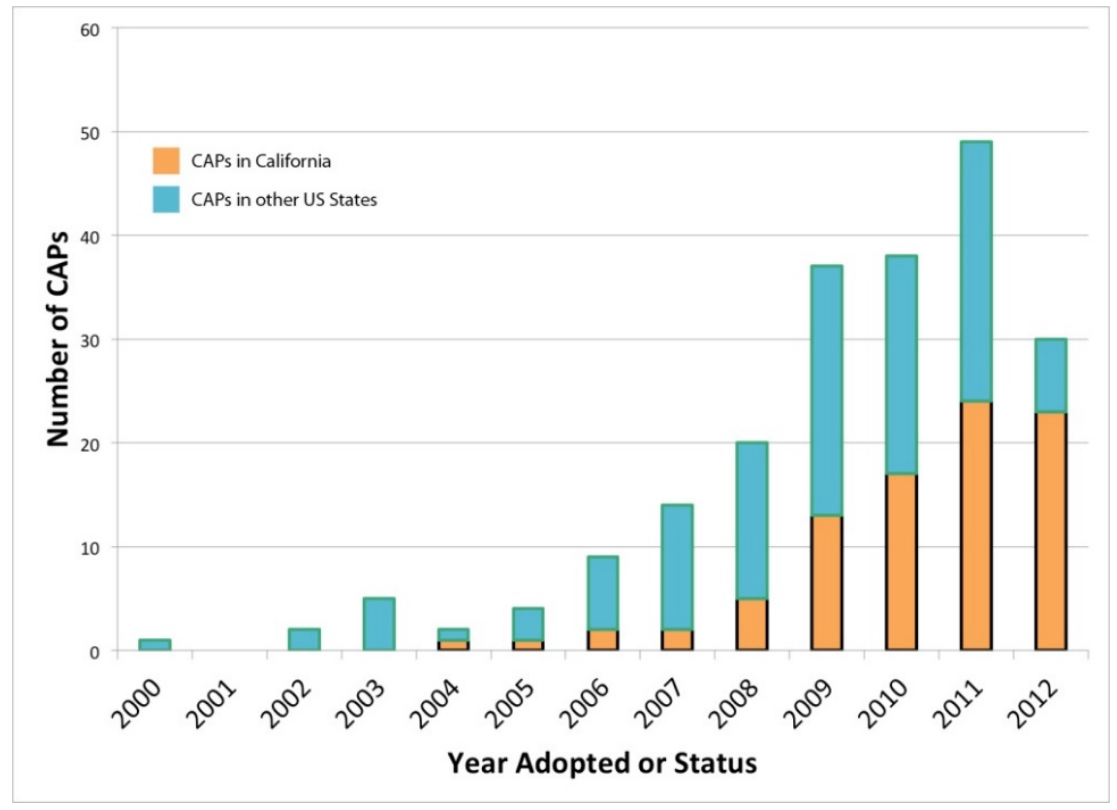

Figure 1: Increase in Climate Action Plan adoption over the past decade. (Source: Boswell, Greve, 2012) 
In California two pieces of legislation have been largely responsible for the plan development.

AB 32 Global Warming Solutions Act (2006) - Set the GHG goal of reaching 1990 emission levels by 2020. (Air Resources Board, 2007)

SB 375 Sustainable Communities and Climate Protection Act (2008) - Enhanced California's ability to reach AB32 goals with local planning. (Air Resources Board, 2013)

CAPs are becoming a powerful component of local planning in which jurisdictions have been willing to invest in meaningful reduction strategies. The reduction strategies all target emissions directly, but often as a by-product improve public health, circulation, open space, and other primary planning elements. For a variety of reasons CAPs are sometimes named energy wise plans, efficiency plans, or something similar; the methodology is often the same but the goal may be to save money rather than reduce emissions.

Thus far emission reduction strategies have been heavily focused on reducing vehicle emissions, reducing vehicle miles traveled, increasing transit mode shares, decreasing building energy use, and decreasing water use. This is largely due to how CAPs calculate emissions. Most plans only consider emissions associated with transportation, electricity use, and waste disposal. These inventories can be deceiving as only emissions produced within a jurisdiction are considered. A product's mining and manufacturing emissions occurring outside jurisdictional boundaries are ignored in CAP inventories. For example, currently if a resident buys a vehicle manufactured elsewhere, only the emissions 
produced by driving the vehicle within jurisdictional boundaries will be included in the GHG inventory. The emissions to mine resources and manufacture the vehicle are not considered. When the production phase is excluded there are missed opportunities to improve global GHG reductions as well as resource depletion. The incomplete inventories can misguide the most beneficial or economical reduction strategies.

Climate Action Plans currently only inventory GHGs emitted directly within a jurisdiction. Emissions are bounded geographically rather than by the comprehensive consumption of a population. While this method provides a manageable scope for Climate Action Plans, it does not provide a complete inventory of the GHGs a population is responsible for. The current methodology of Climate Action Plans does not link communities to their complete carbon footprint. Life Cycle Analysis (LCA) addresses this deficiency and tallies a product's emissions from the mining of resources, through manufacturing, transportation, product use, and then demolition. The intention of CAPs needs to be reinforced. Global warming is a consequence of global emissions. CAP inventories should reflect a community's entire footprint. Life cycle analysis is a more difficult methodology for measuring community emissions in CAPs but may provide valuable insights not captured by the standard practice.

Hazards Planning: LHMPs and Climate Adaptation Plans

Both Local Hazard Mitigation Plans (LHMP) and Climate Adaptation Plans (Adaptation Plans) address hazards planning. In 2012 there were over 20,000 FEMA approved 
LHMPs in the United States and all 50 states had State Hazard Mitigation Plans (SHMP). Figure 2 shows the widespread adoption of the plans. The plan coverage is a direct result of the Disaster Mitigation Act of 2000 which made LHMPs a requirement to receive greater levels of federal assistance following a disaster. The plans are not required, but are incentivized by federal government with the increased funds available to a community. LHMPs highlight a jurisdiction's vulnerability to multiple hazards and outline strategies to mitigate risk to protect life, property, and minimize recovery time.

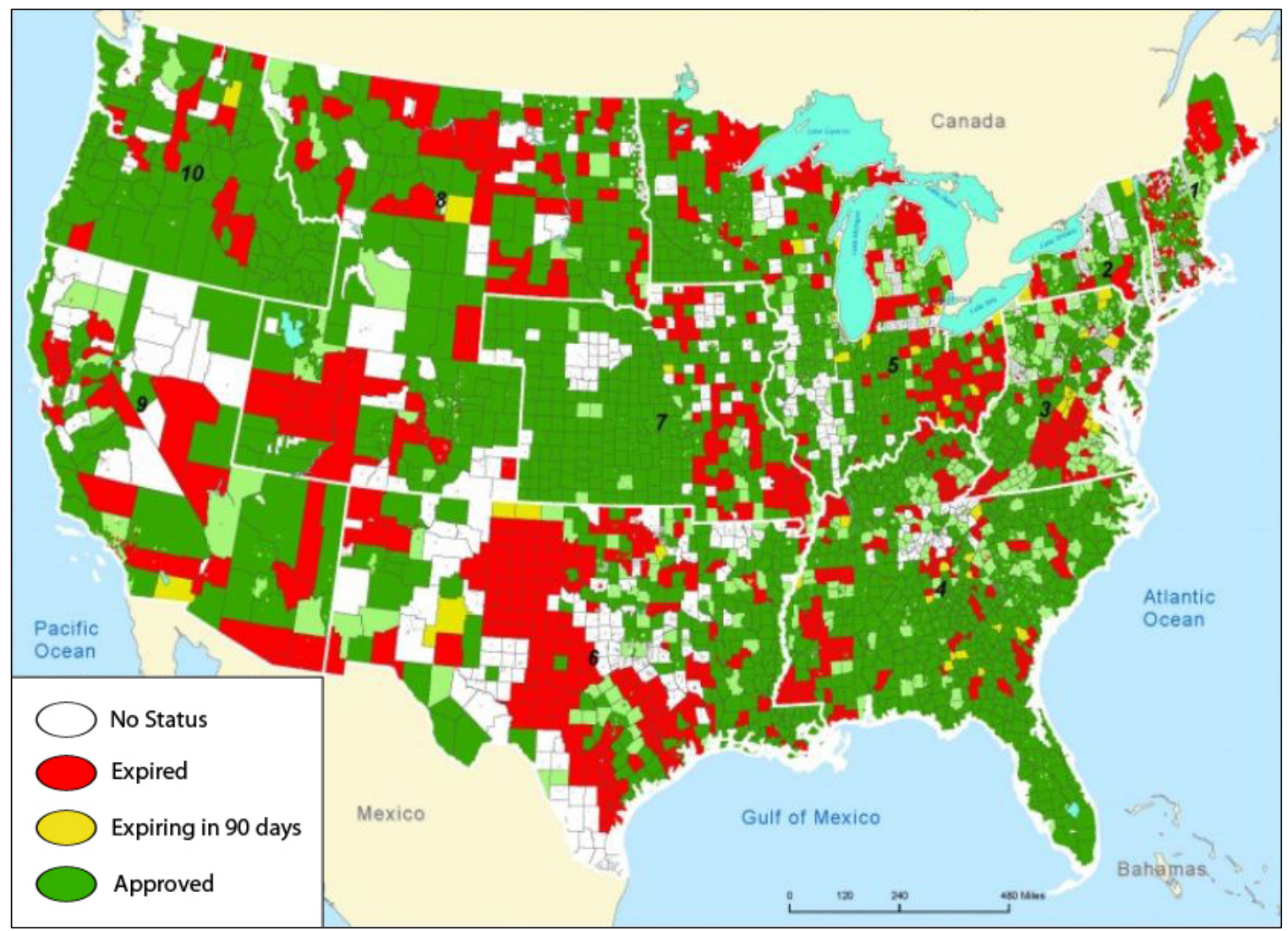

Figure 2: Adopted LHMPs across the United States in 2012. (FEMA, 2013)

Climate Adaptation Plans are very similar, but specifically address hazards that will be caused by climate change. In the past LHMPs have used historic records of past hazard 
events to attempt to prevent repetitive losses from similar events, while Adaptation Plans project future climate hazards, and attempt to limit losses. Adaptation Plans, just as with CAPs can come in a variety of forms and names. Coastal communities may have a sea level rise plan, while an inland community might have an extreme heat plan. Both examples are Adaptation Plans, they are simply focused on a single projected hazard. Unlike LHMPs there are no direct external incentives to produce Adaptation Plans. Because of this, and because the field is young, there are very few plans, and most are focused specifically on sea level rise.

Both LHMP and Adaptation Plans attempt to quantify risk, which is the product of vulnerability and consequence. Vulnerability is often defined as the relationship between the hazard force and the ability to withstand the force. The goal of both plans is to improve the ability to withstand the force and thus decreases losses, or prepare such that when the hazard causes damage the jurisdiction can respond and recover quickly.

Currently CAPs and hazard plans measure different units, greenhouse gasses and losses. However, the process for both is the same, first quantifying a baseline and then quantifying reduction/mitigation strategies, but they are not currently comparable. Life Cycle Assessments (LCA) offer a methodology to bring the plans together in a more comprehensive way. 


\section{Life Cycle Assessments}

A Life Cycle Assessment (LCA) can be used to measure the emission of a product or process from its start of life to the end of life, often described as cradle to grave. Figure 3 shows the terminology often used to describe emissions from a variety of points during a products life. LCA is a popular method used in the sustainability field to measure the emissions of everything from the construction of a home to the preparation of a meal. For some products this can be a very simple process, for others it can be nearly impossible to include all development processes.

\begin{tabular}{|c|c|c|c|c|c|}
\hline $\begin{array}{c}\text { Raw Material } \\
\text { Extraction }\end{array}$ & $\begin{array}{c}\text { Main } \\
\text { Manufacturing }\end{array}$ & $\begin{array}{l}\text { Construction \& } \\
\text { Assembly }\end{array}$ & $\begin{array}{l}\text { Building } \\
\text { Operation }\end{array}$ & $\begin{array}{c}\text { Demolition \& } \\
\text { Waste Disposal }\end{array}$ & $\begin{array}{l}\text { Recycling \& } \\
\text { Reuse }\end{array}$ \\
\hline - & - Cradle to Gate & 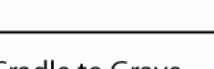 & & & \\
\hline
\end{tabular}

Figure 3: Life Cycle Assessment Phases. Some designations consider cradle to gate as just the first two phases. In this study cradle to gate is the first three. (Created based on Dixit, Fernandez-Solis, Lavy \& Culp, 2010)

For the purposes of this study we are primarily concerned with the LCA of structures. In particular we are most concerned with the cradle to gate phase and the demolition and waste disposal process, which is also described as the embodied phase. A building's life cycle is often broken into two phases, embodied energy and operating energy. Embodied energy includes all processes during material production, construction, and demolition. Operating energy includes all the processes during the use of the building, mostly heating, cooling, and energy for lighting and appliances (Dixit, Fernandez-Solis, Lavy \& Culp, 2010). The use phase of a structure is well documented and already included in 
CAPs. Embodied emissions are not typically measured in CAPs. Despite the incomplete measurement, CAPs are dealing with the majority of the problem, as the bulk of life cycle emissions for buildings and vehicles occur during their use, seen in Table 1. The stratified bar graph shows the GHGs associated with the physical structure in red, while the light blue represents the emissions while the building is in service.

Table 1: LCA Emissions of an Office Building.

\begin{tabular}{|c|c|c|c|}
\hline Phase & Tons $\mathrm{CO}_{2} \mathrm{e}$ & & \multirow{5}{*}{$\begin{array}{l}\text { Demolition } \\
\text { Maintenance } \\
\text { Other Service } \\
\text { Heating Service }\end{array}$} \\
\hline Building Materials & 4,800 & \multirow[t]{2}{*}{50,000} & \\
\hline Construction & 820 & & \\
\hline Electrical Service & 25,000 & \multirow[t]{2}{*}{40,000} & \\
\hline Heating Service & 11,000 & & \\
\hline Other Service & 3,900 & \multirow{2}{*}{ Tons $\mathrm{CO}_{2} \mathrm{e}^{30,000}$} & \multirow{5}{*}{ Electrical Service } \\
\hline Maintenance & 1,600 & & \\
\hline Demolition & 440 & \multirow[t]{2}{*}{20,000} & \\
\hline Embodied Subtotal & 6,060 & & \\
\hline Use Subtotal & 41,500 & \multirow[t]{2}{*}{10,000} & \\
\hline Total & 47,560 & & $\begin{array}{l}\text { Construction } \\
\text { Building Materials }\end{array}$ \\
\hline
\end{tabular}

Studies estimate $10-20 \%$ of a building's emissions is embodied in the cradle to gate and demolition phases of a structure (Hsu, 2009; Blanchard \& Reppe, 1998). The range is due to the variety of building materials, regional conditions, and construction methods. The range can also be due to lower operating energy of high efficiency buildings. An LCA comparison study of a standard and high efficiency home increased construction share of a 50 year building life from 6.3\% to 16.6\%, see Figure 4 (Blanchard, 1998). The more efficient buildings become, the greater the share the embodied phase becomes. The same relationship applies to vehicles. The California Energy Commission estimates 10$20 \%$ of a vehicle's total life cycle emissions are produced in mining and manufacturing 
(TIAX, 2007). These numbers are likely to increase in the future with a greater share of fuel efficient vehicles. The manufacturing phase for high efficiency vehicles will represent a greater share of emissions over the life cycle. Currently nearly all incentives and focus is spent on reducing the use phase emissions of homes and vehicles, with embodied energy rarely considered in the design and construction (Monahan, 2011). The LCA method encompasses all emissions and will direct cities toward more complete strategies for decreasing $\mathrm{CO}_{2} \mathrm{e}$ emissions.

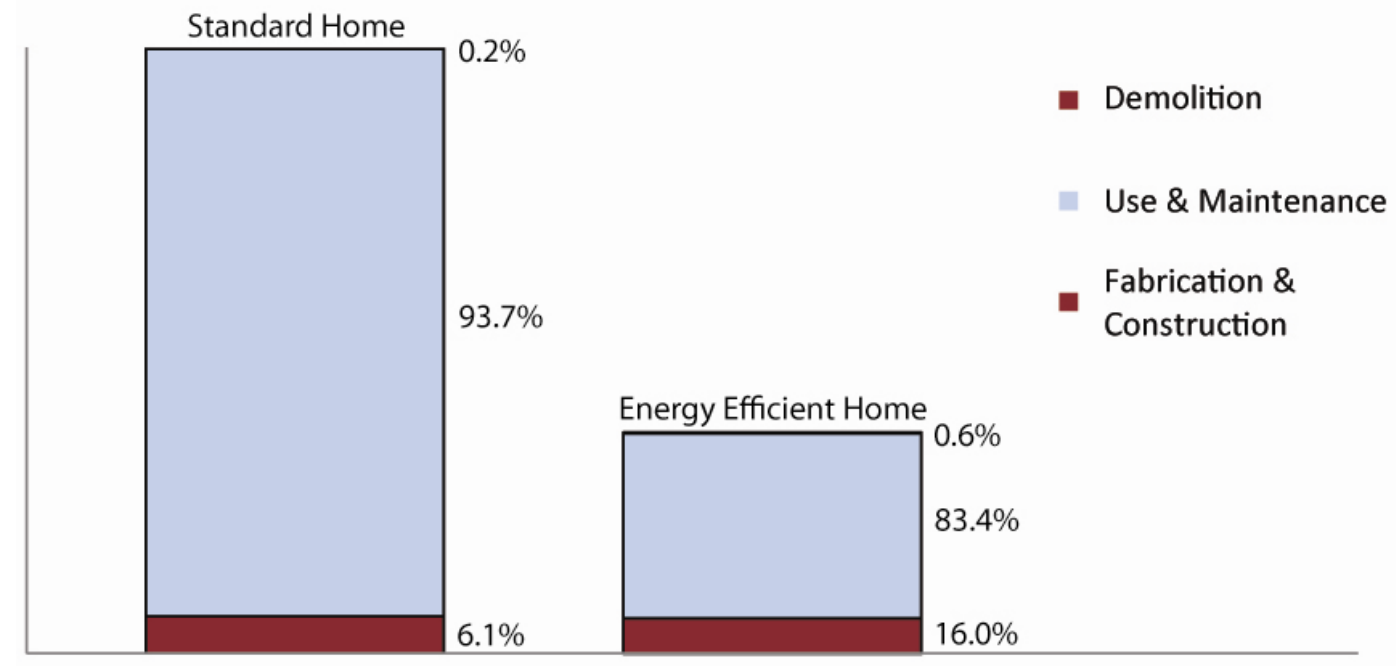

Figure 4: Embodied emissions are a greater share of overall life cycle emissions of energy efficient structures.

Two LCA methods can estimate embodied emissions resulting from disasters: the Economic Input Output method and the Process Based method. The Economic Input Output method (EIO) takes the cost of a project and applies a GHG per dollar ratio to 
determine the emissions impact. The Process Based (PB) LCA uses the quantity or volume of a used resource and calculates the embedded emissions associated with each unit of material. The accuracy of each method is dependent on the sophistication of the LCA inputs. Both methods are desirable for determining GHG emissions produced by disasters because disasters are often quantified by dollars, tons of debris, and damaged units.

\section{Economic Input Output LCA Method}

A number of organizations have developed EIO models of varying detail to take the dollar cost of a project to project the GHG emissions. The models estimate the impact for multiple sectors. Carnegie Mellon University houses a free online calculator that can compute the GHGs associated with nearly 500 commodities and services. The EIO-LCA can specifically calculate the cradle to gate emissions. To use the EIO calculator a sector is selected and a monetary value is input. For example to calculate the emission to produce a $\$ 10,000$ vehicle the auto manufacturing sector is selected and the value $(\$ 10,000)$ is inserted. The calculator then draws from its database and determines the GHG emitted for each process within that sector including the mining and transportation of materials, and generates a GHG value. It is important to note, under this model a $\$ 20,000$ dollar vehicle produces twice the emissions as a $\$ 10,000$ one. This is likely an inaccurate representation making the Carnegie Melon EIO calculator ineffective for individual projects; however when dealing with a city wide or regional impact the values likely average out to match the model.

Page 13 
The Carnegie Mellon University EIO-LCA calculator uses U.S. Department of Commerce economic data. The economic data is reported in 485 separate sectors, and then matched with corresponding emissions data from a number of public sources, including U.S. EPA Toxics Release Inventory and the U.S. Census of Manufactures (Matthews \& Small, 2001). The calculator links nationwide economic data with nationwide environmental and emission data. The calculator is effective when measurement falls within one of the 485 sectors, and less successful for specific LCA studies when a process is not directly represented by a single sector on the list.

\section{Process Based LCA Method}

Most process based methods quantify the GHG per unit of material. A number of material inventories have very comprehensive tables of the GHG's associated with all types of mined resources and common commodities. To calculate emissions of components, the parts are broken down into elementary materials; GHGs for each are then summed together. The accuracy of the LCA is determined by the fit between the actual resource being used and the available inventory value. The precision of component quantities also influences the accuracy of the model. This has been a popular method when studying individual projects or processes. The process based method has been applied to a number of different home types and construction methods. 


\section{Calculating the Embodied Emissions of Buildings}

Because we are interested in a regional wide process based method, average values will have to be assumed using past studies. There are many ways to complete a Process Based LCA, but for this study a $\mathrm{CO}_{2} \mathrm{e} / \mathrm{sq}-\mathrm{ft}$. ratio will be used as the metric to measure

the emissions of buildings. For this to be an effective metric, the average square feet of different structures is necessary as is the percent of reconstruction activity given major and minor damage counts. Below average values are developed for each variable.

Average square foot of single family home, apartment unit, and mobile home. There is a linear relationship between the size of a home and the materials required to build that home. For the analysis the average size of each housing type is necessary. In some cases a local realtor data set might provide local averages, however the US Census also provides average home sizes. As part of its inventory of new construction, the US Census has collected the average square footage of new single-family homes and multifamily buildings since 1978. Figure 5 shows the growth of single-family home sizes. The average square footage of apartment buildings is not provided, but a distribution is. Figure 6 shows this distribution. 


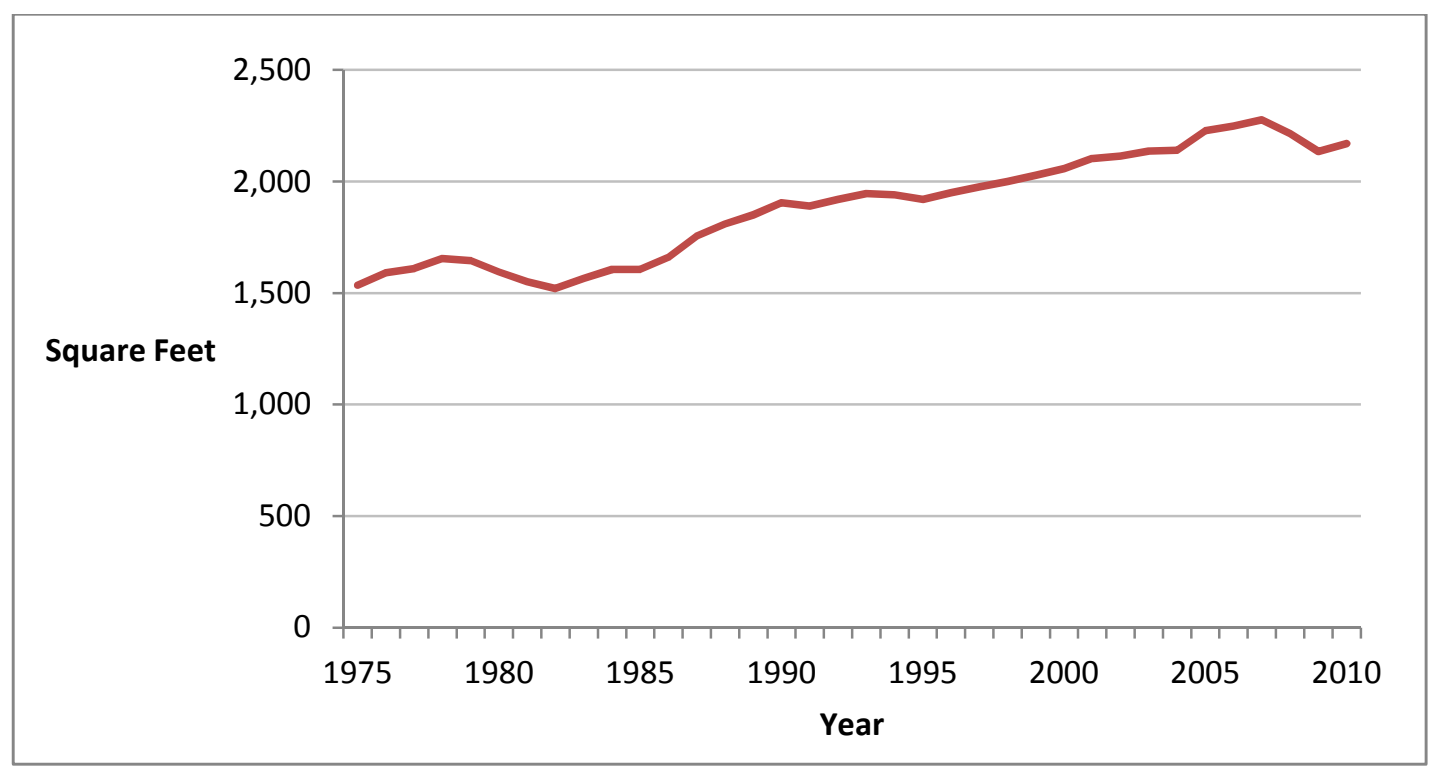

Figure 5: Square Footage of U.S. Single Family Home (1975-2010). (US Census, 2010)

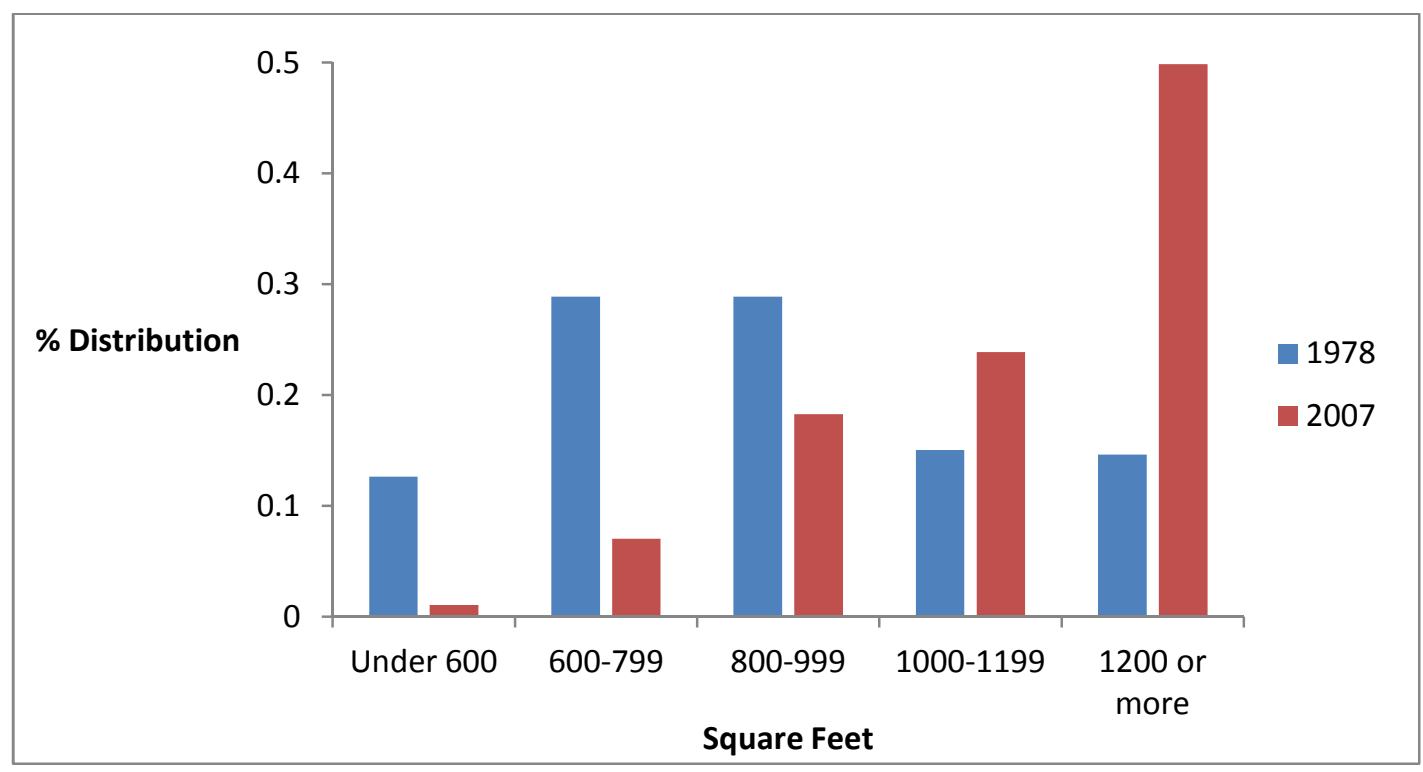

Figure 6: Distribution of U.S. Apartment Floor Areas (1978 \& 2007). (US Census, 2007)

The historic breakdown of multi-family units is no longer an ideal distribution with $49.8 \%$ of units in the greater than 1,200 sq- $\mathrm{ft}$ bin. In addition to the break down by year, the square footage can also be separated into national regions (Northeast, South, 
Midwest, and West). The database provides a general estimate of housing sizes. Local housing databases may provide more accurate estimates for local jurisdictions. The breakdown by age and region provides a more accurate measurement of housing square footage given the housing profile of the jurisdiction studied.

\section{Percent reconstruction of major and minor damage.}

In disasters and in scenario generation structures are often categorized into 3 or 4 categories. For an accurate assessment the dataset must describe what level of repair is represented by each category. This becomes a tricky area to navigate when there is no definition. There are a few methods to inventory damage. In earthquakes Applied Technology Council (ATC) has produced ATC-20, a document and training program for rapid evaluation of damaged structures. FEMA also has a damage inventory system it applies across multiple hazards. For the purposes of this study damage levels are based on the FEMA Preliminary Damage Assessment methodology because of its multi hazard use and because designations are based on rebuilding. The different damage designation levels of structures are destroyed, major, minor, and affected. Under the FEMA definitions, destroyed represents total loss, major damage constitutes greater than $50 \%$ damage, and minor damage represents less than $50 \%$ damage. In each of these damage cases the structure is not immediately habitable; however, the fourth designation, affected, represents a structure that may have some damage but is habitable. The complete definitions of each damage level are included in Appendix A. Despite these breakdowns there is still a large range between each. 
$\mathrm{kg} \mathrm{CO}_{2} \mathrm{e} / \mathrm{m}^{2}$ ratio for each building type.

To generate this ratio a local study could be completed to determine a region specific ratio. No local studies were available for the locations of interest for this study so an average value across a number of literature studies was calculated (Ramesh, Prakash \& Shukla, 2010; Dixit, Fernandez-Solis, Lavy \& Culp, 2010; Hammond \& Jones, 2008). Because the literature is international most reports measure using metric units. To stay consistent with the literature units were maintained for this portion and then converted to feet. Results from a number of studies were compiled into a database. In addition to the $\mathrm{kg} \mathrm{CO} \mathrm{CO}_{2} \mathrm{e} / \mathrm{m}^{2}$ for each study other information was collected: structure size, lifespan, principal structure material, building use, country of study, study reference, embodied energy, operating energy, and total life cycle energy. In most cases the database is incomplete as some studies only included a fraction of the designations. The only attribute that is complete across all studies is the embodied energy value and the reference source. Appendix B shows the inventory table. Figure 7 is a histogram of 73 LCA studies of single family homes and apartments. Figure 8 is a histogram of 35 LCA commercial building studies. 


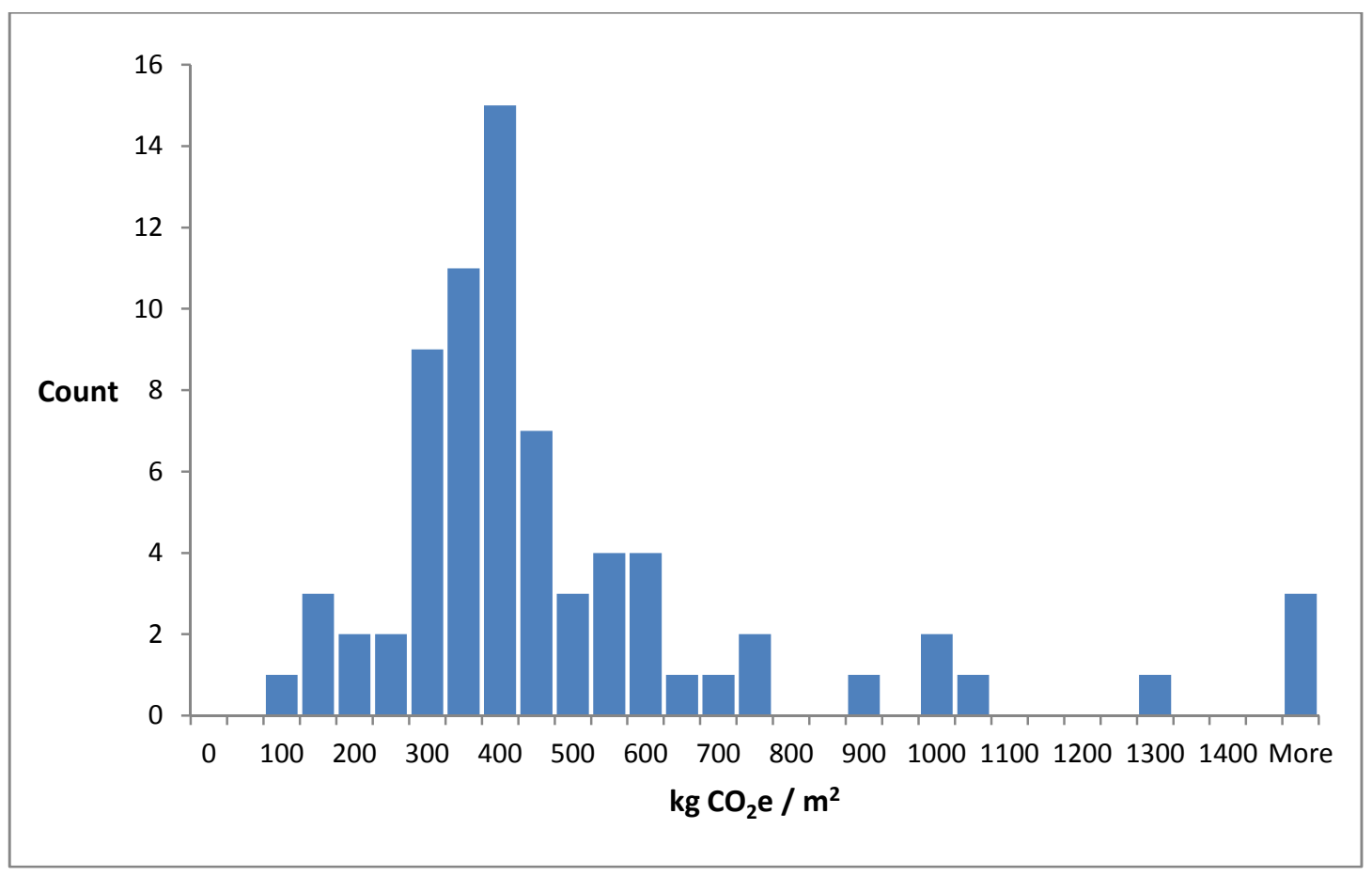

Figure 7: Histogram of $\mathrm{kgCO}_{2} \mathrm{e} / \mathrm{m}^{2}$ for 73 Residential Structure LCAs.

The inventory was compiled using three similar reports that compiled smaller sets of studies. The dispersion is caused by both error within individuals studies and difference in data and boundaries used, as well as the different homes analyzed (construction types and housing types). Timber frame homes, brick and mortar homes are all included in this data set. A study was not completed for apartments versus single family homes because most of the studies did not differentiate between single family and multifamily structures. It can be assumed however that the majority of the studies were for single family homes. The statistical breakdown of residential units is shown in Table 2 . 
Table 2: Statistical Breakdown of 73 Residential Structure PB LCAs $\left(\mathrm{kgCO}_{2} \mathrm{e} / \mathrm{m}^{2}\right)$

\begin{tabular}{lccc} 
& All & $\begin{array}{c}\text { Omit Extreeme } \\
\text { Outliers }(>1176)\end{array}$ & $\begin{array}{c}\text { Omit Mild Outliers } \\
(>848)\end{array}$ \\
\hline Mean & 497 & 409 & 376 \\
Median & 392 & 380 & 368 \\
Mode & $400-450$ & $400-450$ & $400-450$ \\
\hline
\end{tabular}

* The lower bound for outliers in both cases is a negative number.

Depending on which methodology is used to determine outliers there are either 4 or 8 outliers. Excluding the extreme outliers the average $\mathrm{kg} \mathrm{CO}_{2} \mathrm{e} / \mathrm{m}^{2}$ ratio of homes was 409 with a median of 380. Depending on knowledge of local buildings the data set could be used to only consider structures of a certain type to provide a more appropriate breakdown.

The same process was followed for commercial structures. Figure 8 shows the histogram of commercial structures and Table 3 has the statistical breakdown of the studies. Excluding the extreme outliers, the average $\mathrm{kg} \mathrm{CO}_{2} \mathrm{e} / \mathrm{m}^{2}$ ratio of commercial structures was $777,52 \%$ greater than residential structures. 


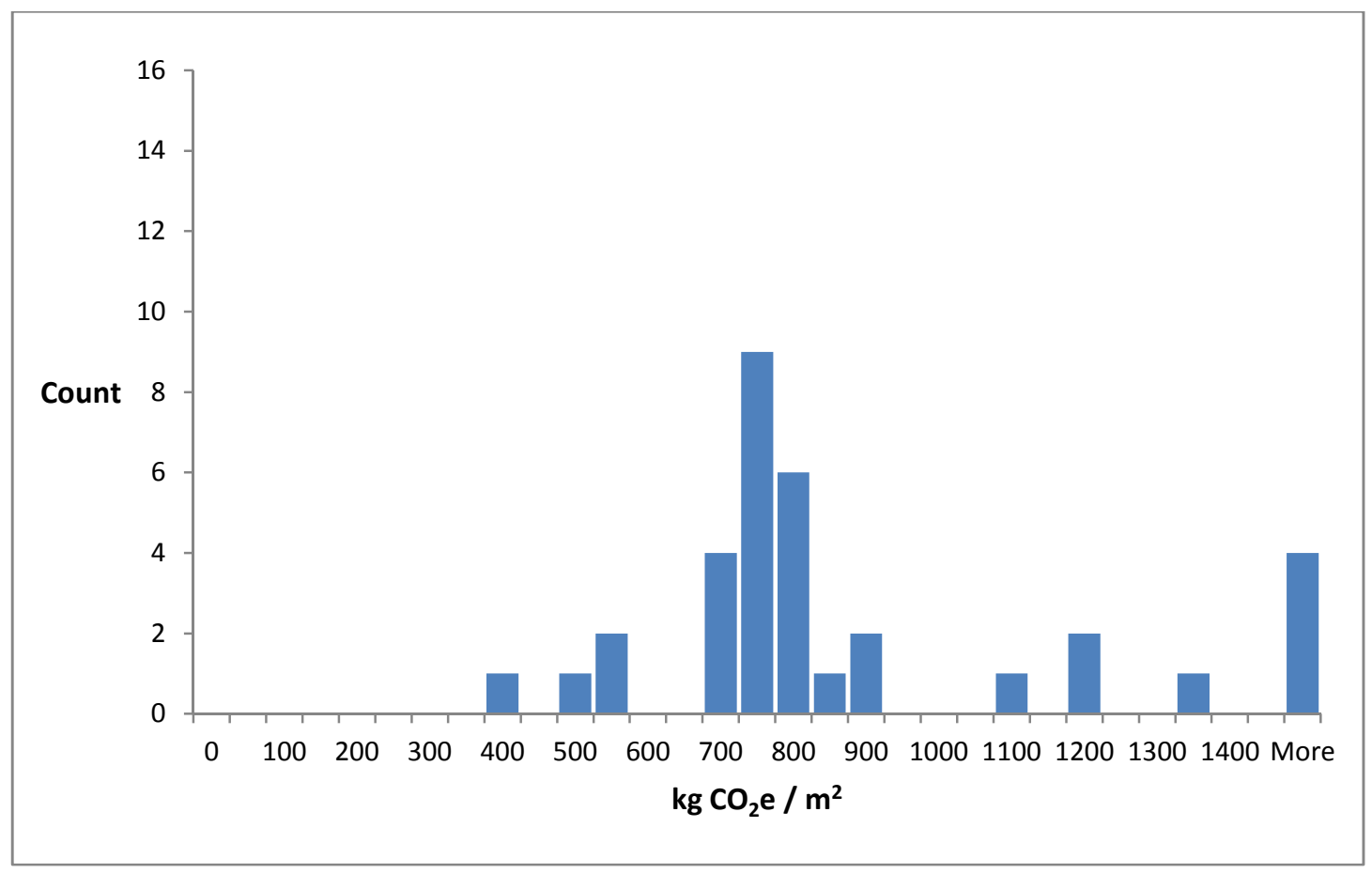

Figure 8: Histogram of $\mathrm{kgCO}_{2} \mathrm{e} / \mathrm{m}^{2}$ for 35 Commercial Structure LCAs.

Table 3: Statistical Breakdown of 35 Commercial Structure PB LCAs $\left(\mathrm{kgCO}_{2} \mathrm{e} / \mathrm{m}^{2}\right)$

\begin{tabular}{lccc} 
& All & $\begin{array}{c}\text { Omit Extreeme } \\
\text { Outliers }(>1466)\end{array}$ & $\begin{array}{c}\text { Omit Mild Outliers } \\
(>1162)\end{array}$ \\
\hline Mean & 910 & 777 & 704 \\
Median & 737 & 731 & 713 \\
Mode & $750-800$ & $750-800$ & $750-800$ \\
\hline
\end{tabular}

* The lower bound for outliers in both cases is less than the smallest value.

The Use of LCA in Plans

Most individual community emission inventories do not use life cycle assessments to measure emissions. Anu Ramaswami of the University of Minnesota and previously the University of Colorado, Denver developed a hybrid life-cycle-based methodology to 
include airline travel, and the embodied energy of food, water, fuel, and concrete (Ramaswami, Hillman, Janson, Reiner \& Thomas, 2008). The objective of including these emissions is to include a more holistic emissions inventory. She recognizes that the standard approach to emission inventories "effectively penalizes producer cities that produce critical urban materials, while giving credit to consumer cities," (Ramaswami et al. 2008). This is the case for cities like Benicia which completed a Climate Action Plan in 2008. The city has a large oil refinery and is home to a number of other large industrial facilities. San Francisco on the other hand is a city that has very few industrial operations. When emissions inventories from 2000 are compared between the two cities the per capita emissions of Benicia are 12.8 times greater than San Francisco, despite the cities being in the same region; see Table 4. While San Francisco has a greater share of public transit ridership, and many other low emission characteristics, their seemingly low emissions in comparison is partially because emission to refine fuel or manufacture products used in San Francisco are not part of their inventory. This is quickly seen in Table 5 which breaks down the community emissions by sector. Benicia and San Francisco are an extreme example of an industrial city and a consumer city.

Table 4: Comparison of Two Bay Area Cities per Capita Emissions

\begin{tabular}{lcc} 
& Benecia & San Francisco \\
\hline Total City Emissions $\left(\mathrm{MT} \mathrm{CO}_{2} \mathrm{e}\right)^{1,2}$ & $4,000,000$ & $9,700,000$ \\
Population $2000^{3}$ & 26,865 & 776,733 \\
Per Capita Emissions (MT per person) & 149 & 12 \\
\hline${ }^{1}$ City of Benicia, (2008) & & \\
${ }^{2}$ City of San Francisco (2004) & & \\
${ }^{3}$ US Census Profile of Demographic Characteristics (2000) &
\end{tabular}


Table 5: Comparison of Two Bay Area Cities, Percent Emissions by Sector

\begin{tabular}{lcc} 
& Benecia (2000) & San Francisco (1990) \\
\hline Transportation & $4 \%$ & $51 \%$ \\
Industrial \& Commercial Buildings & $94 \%$ & $30 \%$ \\
Residential Buildings & $1 \%$ & $19 \%$ \\
Solid Waste & $1 \%$ & - \\
\hline${ }^{1}$ City of Benicia, (2008) & & \\
${ }^{2}$ City of San Francisco (2004) & &
\end{tabular}

The standard methodology used by San Francisco has a drastic impact on what type of reduction strategies are developed for a city. For example, in the 2004 San Francisco Climate Action Plan all the emissions were from building energy use and transportation. This prevents a number of emission reducing solutions from being considered. Developing a demand-centered inventory method allows for greater reduction strategies.

"Incorporating key urban materials into city-scale GHG inventories can spur materials recycling and conservation as well as alternative materials policies (e.g. green concrete) in cities...Thus city-scale GHG policy development and analysis can be strongly impacted by the underlying GHG inventory methods and inclusions." (Ramaswami, 2008)

Using a hybrid method of material flow analysis and life cycle assessment Ramaswami estimated the emissions of key urban materials, air travel, and conventional city-scale boundary-limited direct emissions for the Denver, CO. The added categories represent $25 \%$ of the annual emissions for the city. Figure 9 shows the added categories in red, and the conventional ones in blue. 


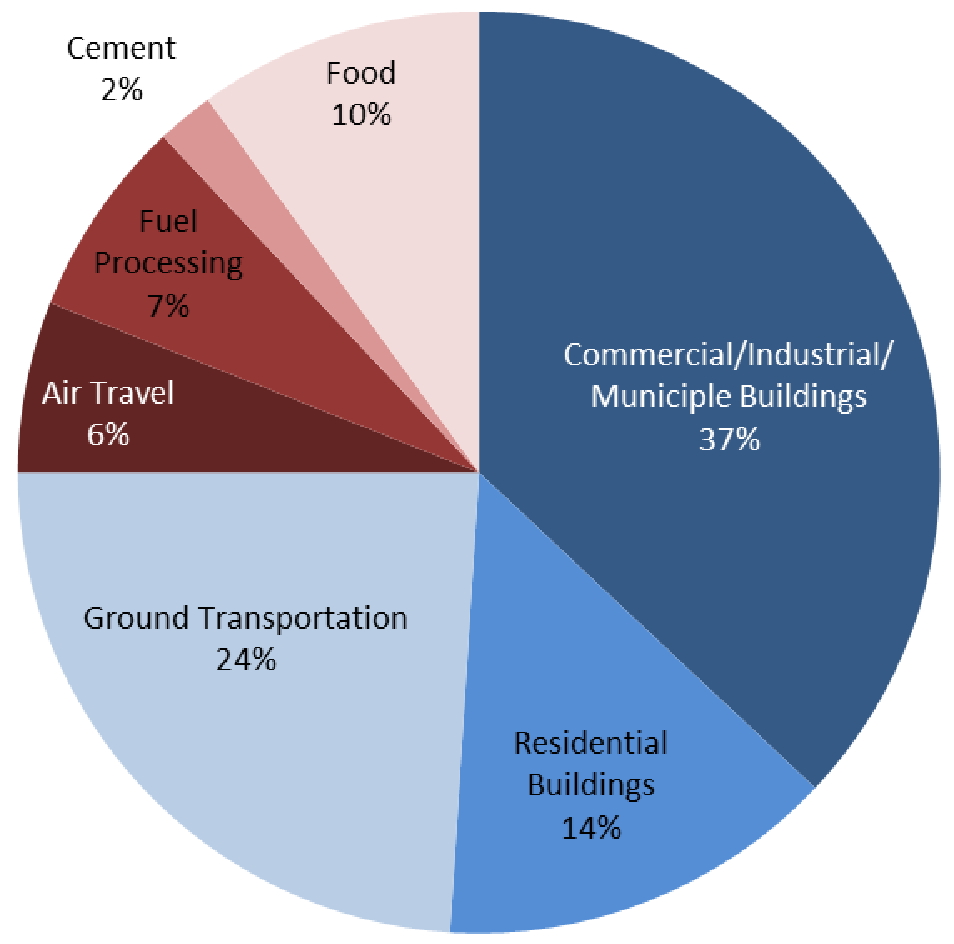

Figure 9: 2005 Denver emissions using the hybrid methodology (Ramaswami et al., 2008).

The methodology used by Ramaswami is very similar to the methodology proposed in this thesis. Ramaswami and other researchers have since generated similar inventories for eight other US cities (Hillman \& Ramaswami, 2010). The research developed focuses on easiest to measure discrete sectors. Because concrete and refining facilities are often single large facilities measuring them specifically is much easier than studying all industry. This thesis attempts a similar demand based life cycle assessment that will provide an assessment not just of concrete, but of all building materials. Ramaswami's research will be discussed in greater detail in Section 4.1 when double counting of emission is introduced. 


\section{Quantifying Disasters}

For life cycle assessments to be used to model the GHGs associated with hazard events, disasters must be measured in either dollars or debris. In either case the quality of data collected will determine the accuracy of an emissions calculation. Initial estimates of both dollars and debris are frequently reported but often measured as single numbers rather than detailed records. For EIO and PB LCAs detailed breakdowns for dollar losses and debris are needed. Following an event many organizations assign expected disaster losses within a day of an event, with more refined estimates weeks, months, and years following. Similarly, the quantity of homes destroyed or damaged is often reported. Destroyed units are straight forward to quantify but damaged units are more difficult. As mentioned in Section 2.2.2 even if units are designated with major, moderate, and minor, or red, yellow, and green, it is difficult to judge how much reconstruction will occur.

Private insurers and governments place dollar values on events as both often write sizeable checks to the affected regions. These dollar amounts can represent a number of different things. In disasters there are direct losses (damaged capital), and indirect losses (business interruption). Both have a substantial economic and social impact, but for the purposes of GHG emissions direct losses are most relevant. Direct damage reflects the amount of material goods to be rebuilt. The difficulty with reported disaster losses provided with insurance organizations is it is often unclear what is included in the estimate. Only a fraction of direct losses may be included and indirect losses may be included. For example, insurers may only provide a percentage of the cost to repair a damaged structure depending on the policy but may include payouts for temporary 
residence, which are unrelated to the rebuilding. For the EIO method to provide an accurate assessment, direct losses must be separate from indirect losses and values must be broken into sectors like residential reconstruction, auto repair, and other losses.

Debris can be measured in a number of different ways to be used by Process Based LCAs. The standard Process Based method requires data on the volume or weight of each material or component damaged; for example, 20 tons of drywall. A life cycle inventory is then used to assign an emissions multiplier specific to that material. Some inventories are basic and may have a blanket multiplier for a drywall, while more robust tables may provide brand specific estimates. While this type of data would provide ideal data for an LCA, it is unrealistic to expect this level of detail of disaster debris or materials brought in for reconstruction at a regional scale. Rather larger components can be measured to simplify the necessary reporting. Counting the number of homes and businesses destroyed is a more common reported figure rather than the tons of drywall and timber debris. For this method, the inventory of LCAs is applied to disaster data. The disaster data can be matched with existing LCA studies to quantify the GHG's of disaster reconstruction.

With good data, either method can be used to calculate the GHG produced by previous disasters or scenarios. Chapter 3 will explore both methods and compare the results of each life cycle method. 


\section{CHAPTER 3}

\section{Estimated GHG of Past U.S. Disasters}

Case studies of past events are used to examine the LCA GHG conversion methodologies. The EIO and PB methodologies were used to quantify the emissions of Hurricane Andrew and the Northridge Earthquake.

\section{Hurricane Andrew}

In August of 1992 Hurricane Andrew, a category 4 storm, made landfall in South Florida. At the time Andrew was the third strongest recorded hurricane to strike the United States (Comerio, 1998). More recently Katrina and Sandy have reinforced the frequency and scale of hurricanes. Hurricane Andrew resulted in over $\$ 22$ billion dollars in losses, with residential structure damage representing half the total losses. Over 28,000 housing units were destroyed in the hurricane, and another 107,000 were damaged. The EIO method explores the emissions of all damage, while the PB method specifically focuses on residential structures. Table 6 shows the dollar losses and resulting emissions using the EIO method, while Table 7 contains damage units and resulting emissions using the PB method.

Following the hurricane, West and Lenze (1994) collected damage estimates and categorized the dollar losses into 19 sectors. These losses were input into Carnegie Melon's EIO calculator to generate the emissions required to replace damaged components. The EIO calculator matched inputs like residential structure construction to 
residential damage. In some cases the inputs for the calculator did not match with a damage category. For example, to generate a GHG associated with the residential contents category, upholstered household furniture manufacturing was assumed an equivalent sector (a more extensive study may recommend using a share of multiple sectors based on a study of typical building contents). After the emissions of each sector were tabulated they were totaled. This total does not represent the emissions resulting from the disaster. This would be the case if all of the structures and contents had just been constructed and manufactured. Old structures nearing the end of their life cycle do not represent a total life cycle loss as they would soon be replaced regardless of the hurricane. For LCAs construction and demolition costs are annualized over the life of the building. For the purposes of this study the total was divided in half assuming the average damaged building was halfway through its life. Again more detailed local information may suggest a different value if the housing stock was newer or older. Using the EIO method to replace Hurricane Andrew damage 7.0 million tons of $\mathrm{CO}_{2} \mathrm{e}$ was emitted, equivalent to 786 million gallons of gasoline consumed (EPA, 2013).

Better knowledge of the local building stock may allow for different assumptions to be made. Additionally, a more refined breakdown of losses would provide a more accurate emission conversion. For example, if residential contents had been further divided into appliances, furniture, and goods, the EIO calculator would be able to provide accurate estimates for each. 
Table 6: Hurricane Andrew Damage and EIO GHG Estimate

\begin{tabular}{|c|c|c|c|}
\hline Category $^{1}$ & $\begin{array}{c}\text { Damage } \\
\text { (\$ Millions) }^{1}\end{array}$ & $\begin{array}{l}\text { EIO Emission } \\
\left(\mathrm{MTCO}_{2} \mathrm{e}\right)^{2}\end{array}$ & EIO Detailed Sector ${ }^{2}$ \\
\hline Residential Structures & 10,481 & $6,910,000$ & Permanent single/multi-family structures \\
\hline Mobile Homes & 289 & 169,000 & Motor Home Manufacturing \\
\hline Residential Contents & 5,385 & $3,090,000$ & Upholstered household furniture \\
\hline Commercial Structures & 1,142 & 673,000 & Non-residential commercial structures \\
\hline Commercial Contents & 1,080 & 501,000 & Office Furniture Manufacturing \\
\hline Autos & 473 & 266,000 & Automobile Manufacturing \\
\hline Boats & 591 & 314,000 & Boat Building \\
\hline Airplanes & 45 & 16,700 & Aircraft Manufacturing \\
\hline Agriculture Structures & 277 & 121,000 & Nonresidential manufacturing structures \\
\hline Agriculture Equipment & 48 & 31,200 & Farm Machinery and Equipment \\
\hline Agriculture Inventories & 130 & 329,000 & All other crop farming \\
\hline Utilities & 420 & 262,000 & Nonresidential maintenance and repair \\
\hline State/Local Govt. Structures & 437 & 257,000 & Non-residential commercial structures \\
\hline State/Local Govt. Pub. Works & 410 & 256,000 & Nonresidential maintenance and repair \\
\hline State/Local Govt. Equipment & 275 & 147,000 & Commercial and industry manufacturing \\
\hline Federal Govt. AFB & 1,007 & 593,000 & Non-residential commercial structures \\
\hline Federal Structures & 119 & 70,100 & Non-residential commercial structures \\
\hline Federal Equipment & 25 & 13,300 & Commercial and industry manufacturing \\
\hline Nonprofit & 15 & 8,840 & Non-residential commercial structures \\
\hline Total & 22,649 & $14,028,140$ & \\
\hline Disaster Caused Total & - & $7,014,070$ & \\
\hline
\end{tabular}

The Process Based method was also applied to Hurricane Andrew using destroyed and damaged residential units rather than dollar values. The number of destroyed and damaged units of each housing type was taken from a data set in Comerio, 1998. Given these estimates Table 7 converts the number of damaged and destroyed units into emissions. To accomplish this conversion a number of variables are needed, shown in Table 8. Section 2.2.2 explained the methodology used to develop values for the average residential square footage, the $\%$ reconstruction of major and minor damage, and the 
$\mathrm{CO}_{2} \mathrm{e} /$ sq-ft ratio. Equation 1 shows the calculation used to take damage units and generate $\mathrm{CO}_{2} \mathrm{e}$.

Table 7: Hurricane Andrew Damage to GHG Estimate (Process Based)

\begin{tabular}{llrr} 
Housing Type & Damage Category & $\begin{array}{r}\text { Housing } \\
\text { Units }\end{array}$ & \multicolumn{1}{c}{$\begin{array}{r}\text { PB Emissions } \\
\text { (MT CO2e) }\end{array}$} \\
\hline \multirow{3}{*}{ Single-Family } & Destroyed & 8,373 & 568,620 \\
& Major Damage & 37,245 & $1,580,845$ \\
& Minor Damage & 40,632 & 689,842 \\
\hline \multirow{3}{*}{ Multi-Family } & Destroyed & 10,719 & 356,730 \\
& Major Damage & 13,995 & 291,097 \\
& Minor Damage & 13,889 & 115,557 \\
\hline \multirow{3}{*}{ Mobile Homes } & Destroyed & 8,974 & 223,992 \\
& Major Damage & 1,100 & 17,160 \\
& Minor Damage & 519 & 3,239 \\
\hline \hline & Total & 135,446 & $3,847,081$ \\
& Disaster Caused Total & - & $1,923,541$ \\
\hline
\end{tabular}

${ }^{1}$ Comerio (1998) 


\section{Table 8: List of Variables used for Process Based Estimate}

\begin{tabular}{lrl}
\multicolumn{1}{c}{ Variable } & Value & Units \\
\hline Damage State $^{1}$ & & \\
\hline Destroyed & 1 & - \\
Major & 0.625 & - \\
Minor & 0.25 & - \\
Area per Unit (1978, South) ${ }^{2,3}$ & & \\
\hline Single-Family & 166 & $\mathrm{~m}^{2} /$ unit \\
Multi-Family & 81 & $\mathrm{~m}^{2} /$ unit \\
Mobile & 61 & $\mathrm{~m}^{2} /$ unit \\
Emissions Ratio & & \\
\hline Residential & 409 & $\mathrm{kgCO}_{2} / \mathrm{m}^{2}$ \\
* Values are assumptions based on the following sources. \\
${ }^{1}$ FEMA, 2012. Preliminary Damage Assessment Methodology. \\
${ }^{2}$ US Census, 2010. Characteristics of New Single-Family Houses. \\
${ }^{3}$ US Census, 2007. Characteristics of New Multifamily Buildings. \\
${ }^{4}$ Section 2.2.2
\end{tabular}

\section{EQUATION 1}

Variables: Disaster $\mathrm{CO}_{2}=(\#$ of Units $) \times($ Damage State $) \times($ Area Per Unit $) \times($ Emissions Ratio $)$

Units: $M T \mathrm{CO}_{2} e=($ Housing Unit $) \times\left(\frac{\mathrm{m}^{2}}{\text { Housing Unit }}\right) \times\left(\frac{\mathrm{kgCO}_{2} e}{\mathrm{~m}^{2}}\right) \times\left(\frac{\mathrm{MT}}{1000 \mathrm{~kg}}\right)$

Just as with the EIO method the values were totaled and then divided by two to represent the units being halfway through their lifecycle. Just as with the EIO model a more complete damage data set would provide for a more accurate conversion. For residential structural damage the Process Based method resulted in 1.9 million tons of $\mathrm{CO}_{2} \mathrm{e}$. For the same damage sector the EIO model resulted in 3.5 million tons of emissions, 1.84 times greater emissions. There are three likely causes for the difference in the results; 
methodological differences, inaccurate damage assessments, and/or inaccurate assumptions.

Table 9: Comparison of EIO and PB LCA Methodologies

\begin{tabular}{lll} 
Category & ElO Model & PB Model \\
\hline Residential Structures & $3,539,500$ & $1,923,541$
\end{tabular}

Comparison of Methodology Results

Multiple studies have recognized a similar relationship between EIO and Process Based methods. In a study of embodied emissions of residential buildings EIO analysis resulted in a nearly $90 \%$ greater carbon footprint than the Process Based method (Nassen, Holmberg, Wadeskog \& Nyman, 2006). This is largely due to the further reaching boundaries of EIO assessments. The EIO method does a better job of measuring entire supply chains compared with PB methods. PB LCA studies often only measure the greatest draws of emissions in to a study, and only trace emissions back to a certain point, bounding the assessment. The EIO calculator more easily measures a complete supply chain to manufacture any product (Sharrard, Matthews \& Ries, 2008; Matthews et al., 2001). When both methodologies are broken down in detail and only Process Based emissions are considered in EIO assessments (in essence bounding EIO models), EIO's are only $20 \%$ greater (Nassen et al., 2006). The difference could be because of this methodology discrepancy between EIO and Process Based models, and it could also be due to inaccuracy in the damage data resources or assumptions made in the process. 
Damage assessments both measured in dollars and by units have shortcomings. There is a rush to generate damage estimates in the aftermath of an event, but little reporting on the final counts. In many disasters the damage estimates in dollars do not line up with the number of damaged structures.

"Two years after the [Northridge] earthquake, losses and claims reported by insurance companies were wildly out of sync with the inspection estimates of $\$ 1.5$ billion in damages. Insurance companies have reported nearly four hundred thousand earthquake-related claims (of which two-thirds are residential), with paid claims totaling more than $\$ 12$ billion. The discrepancy is similar to those in Hurricanes Hugo and Andrew, in that the number of claims was two to three times the number of single-family homes inspected. This is partially a function of the inspection process, done as a safety assessment rather than a realistic damage assessment." (Comerio, 1998).

In the case of Hurricane Andrew over 280,000 claims were paid to home owners alone (Comerio, 1998). This is more than double the 135,000 units used for the process based methodology in Table 8 . While the majority of these uncounted units may have received only minor damage, it is damage that was included in the EIO method, and not the PB one.

Lastly, in both the EIO and PB methodology there were a number of assumptions. EIO sectors were matched with the best available fit (residential contents $=$ upholstered household furniture). For the PB-LCA values of percent of structure damage per damage 
state were assumed. Both could account for some of the discrepancy between the two methods.

Despite the somewhat large discrepancy between the two life cycle assessments as a first pass they offer results on the same order of magnitude. Additionally, both the LCA and hazards literature suggests this is common. For life cycle analysis EIO models are often greater than PB models, and for hazards insurance claims often outnumber the number of units included in a damage assessment inventories. In the case of both error sources it is likely that improvements would close the gap in the two methodologies. In the case of EIO and PB methodologies the ability of the PB method to more completely measure emissions would close the gap. Similarly, if the number of damaged housing units and other components are more completely recorded in comparison to the financial reports the gap will close. These are issues for both fields as a whole to work toward improving so that the methods are equivalent. Moving forward either method would be appropriate. The variables of the most robust data source, and an understanding of the data should govern which method is used. Clearly communicating which method was used should provide an accurate baseline from which to measure progress against in the future, making either method appropriate for measuring emissions.

\section{Northridge Earthquake}

In January 1994, a moment magnitude 6.7 earthquake rocked the Los Angeles basin. The 6.7 earthquake represented a moderate sized event for the region; earthquakes as large as 
8.0 are plausible in Southern California. Table 10 highlights Northridge damage and the resulting emission calculations. The same EIO methodology described for Hurricane Andrew was duplicated to calculate the Northridge emission estimate. Not surprisingly the results are very similar to Hurricane Andrew as both had relatively similar losses. Because both events had the similar overall losses, $\$ 22.6$ and $\$ 25.7$ billion, and the EIO methodology uses monetary losses to estimate emissions the results should be similar. Additionally, the ratio of loses where somewhat similar. In addition to the similarity in losses, the use of national data in the Carnegie Mellon EIO calculator ignores any regional differences between the damaged structures and contents in each region. Information about the regional building stock would result in a more refined analysis.

Table 10: Northridge Earthquake Damage and EIO GHG Estimate

\begin{tabular}{|c|c|c|c|}
\hline Category $^{1}$ & $\begin{array}{c}\text { Damage } \\
\text { (\$ Millions) }^{1}\end{array}$ & $\begin{array}{l}\text { ElO Emission } \\
\left(^{(\mathrm{MT} \text { CO2e })^{2}}\right.\end{array}$ & EIO Detailed Sector ${ }^{2}$ \\
\hline Residential Buildings & 12,651 & $8,340,000$ & Permanent single/multi-family structures \\
\hline Commercial Buildings & 4,854 & $2,860,000$ & Non-residential commercial structures \\
\hline Public Buildings & 6,502 & $3,830,000$ & Non-residential commercial structures \\
\hline Freeways \& Bridges & 655 & 401,000 & Combination construction \& mining \\
\hline Miscellaneous & 1,042 & 483,000 & Combination construction \& machinery \\
\hline Total & 25,704 & $15,914,000$ & \\
\hline Disaster Caused Total & - & $7,957,000$ & \\
\hline
\end{tabular}




\section{CHAPTER 4}

\section{Including Disaster Produced GHGs In CAP Inventories}

Thus far only past disasters have been quantified. To be helpful, future disaster loss estimates must be projected just as in LHMPs and Adaptation Plans. To match the format of Climate Action Plans disasters must be annualized. Using insurance models or open source programs like HAZUS, local jurisdictions can annualize their hazards risk if staff/consultants are technically proficient. Without the necessary skills other state resources provide a thorough baseline of data that can be adapted for measuring the annualized GHG emissions of disaster losses. The California Geologic Survey (CGS) has broken down annualized earthquake losses by census district (Chen, Wills, 2011). Using the methods in the previous disaster case studies, the annualized hazard risk can be converted into GHG emissions to be included in a GHG inventory, using annualized HAZUS data.

Disasters represent large GHG peaks in an otherwise consistent emissions pattern. The process of annualizing infrequent events is simply the summation of the probability of each event with the resulting damage given that event. Risk quantified using Equation 2 is the product of the vulnerability and the consequence. Equations 3 and 4 breakdown how to quantify structure vulnerability and consequence. 
Equation 2: Annualized Risk $=($ Consequence $) \times($ Annualized Vulnerability $)$

Equation 3: Annualized Vulnerability $=\sum_{z}($ Prob of Occur. $\mid z) \times(\%$ of damaged struc. $\mid z)$

Equation 4: Consequence $=(\#$ of units in study area $) \times($ rebuild cost per unit $)$

$\mathbf{z}=$ The range of hazard levels. For earthquakes this would be magnitudes 1-10.

Probability of Hazard = Taken from annual prob. of hazard occurrence for respective magnitude $\mathrm{z}$.

\% of damaged buildings $=$ Value is taken from the fragility curve for respective magnitude $\mathrm{z}$.

Figure 10 shows an iteration of Equation 3 graphically for $z=7.0$. To solve the equations building fragility curves and the annualized seismic probabilities are needed. HAZUS has these variables and uses this methodology to generate reports of annualized building loss by census district. It can generate data in terms of the number of damaged/destroyed structures as well as the annualized building earthquake loss in dollars. HAZUS data sets were used primarily because that is what the CGS study used, and it is a popular method for many hazard mitigation plans. For specific building inventories more refined fragility curves can be applied to more appropriately measure the expected performance of that building stock. For city wide, regional and state assessments HAZUS remains the best option. 


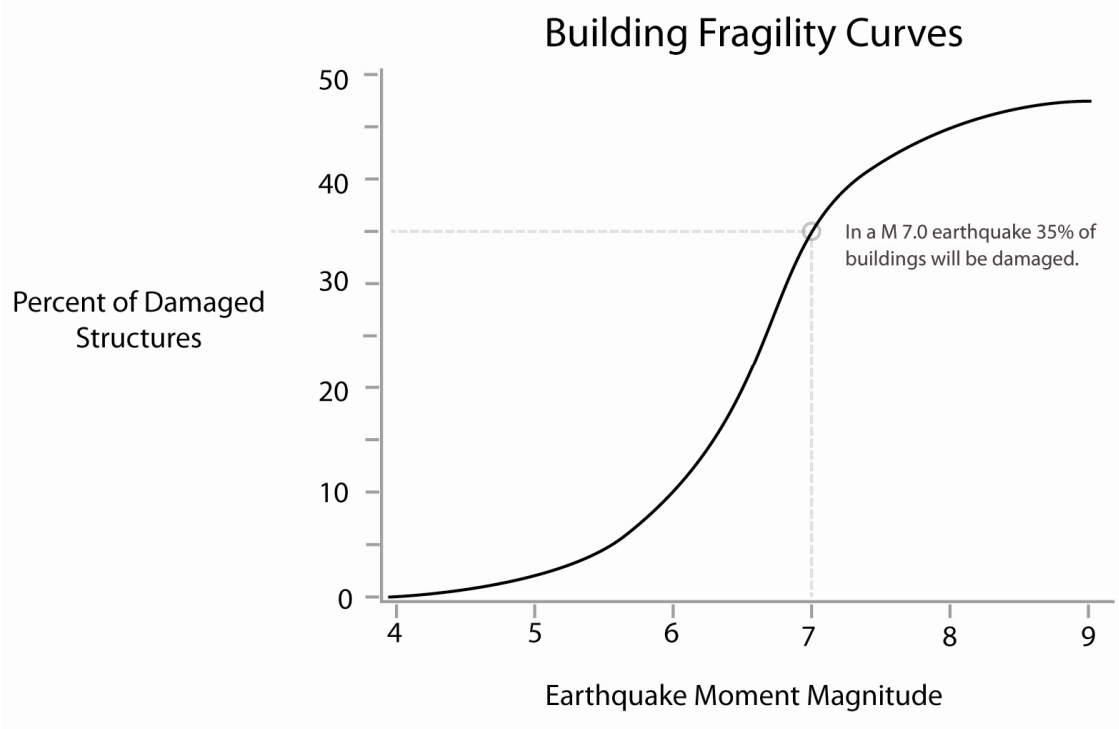

Annual Probability of Earthquake Occurance

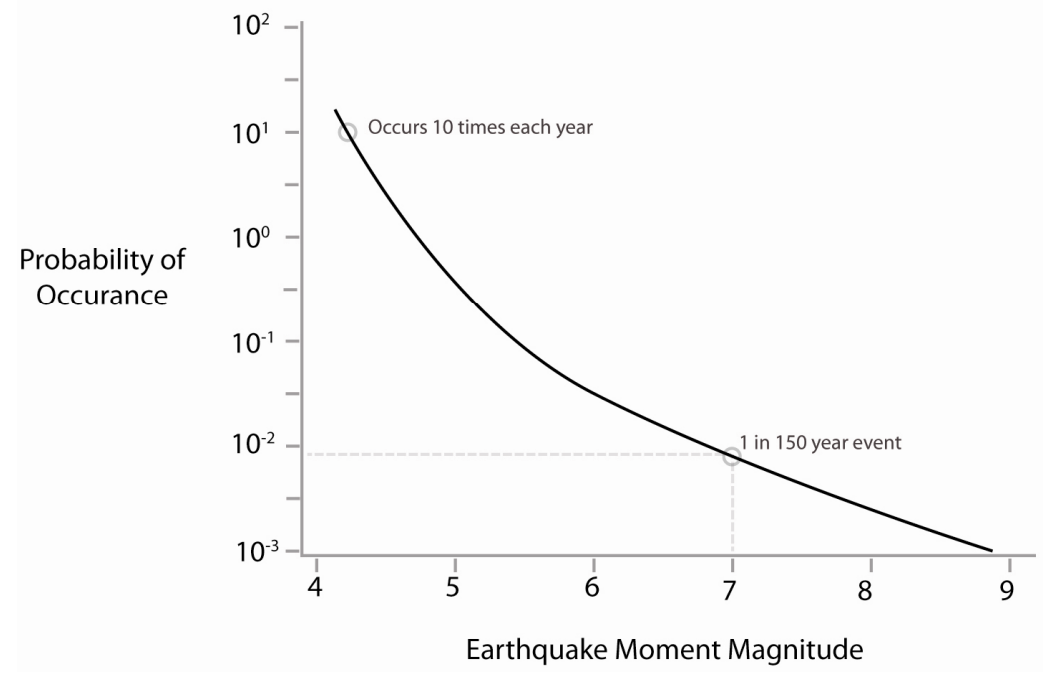

Figure 10: Variables used to calculate the annualized building vulnerability.

To test the annualized methodology four Bay Area cities were chosen as case studies. San Francisco, Oakland, Alameda, and Berkeley were chosen because they all had completed Climate Action Plans and are in the Metropolitan Statistical Area with the second greatest annualized building earthquake risk in California (Chen, 2011). Figure 
11 is a map of the HAZUS data used. The white gaps in the map are Piedmont and Emeryville which were not included in the assessment. The HAZUS data provides the annualized building loss in dollars for each census district and also has the total building value for the census district. By dividing the annualized building loss by the total building value the annualized percent loss is known. This value could be used for a PB LCA method. If the total number of structures for a jurisdiction were known the annualized percent loss could be multiplied by the total number of buildings resulting in the annualized number of buildings destroyed by earthquakes. Many cities have a basic inventory of their buildings, while some may only have a database of parcel numbers with no attribute information. Using the EIO LCA method, the original building loss in dollars for each census district can be used to generate an annualized GHG emission for each jurisdiction. To get rough estimates all building loss is assumed to be residential buildings. This is a conservative estimate because as shown in section 2.2.2 residential structures have a smaller $\mathrm{GHG} / \mathrm{m}^{2}$ compared to commercial structures. If the share of commercial structures were applied with a different $\mathrm{GHG} / \mathrm{m}^{2}$ the annualized emissions would increase. This would require more detailed analysis. 


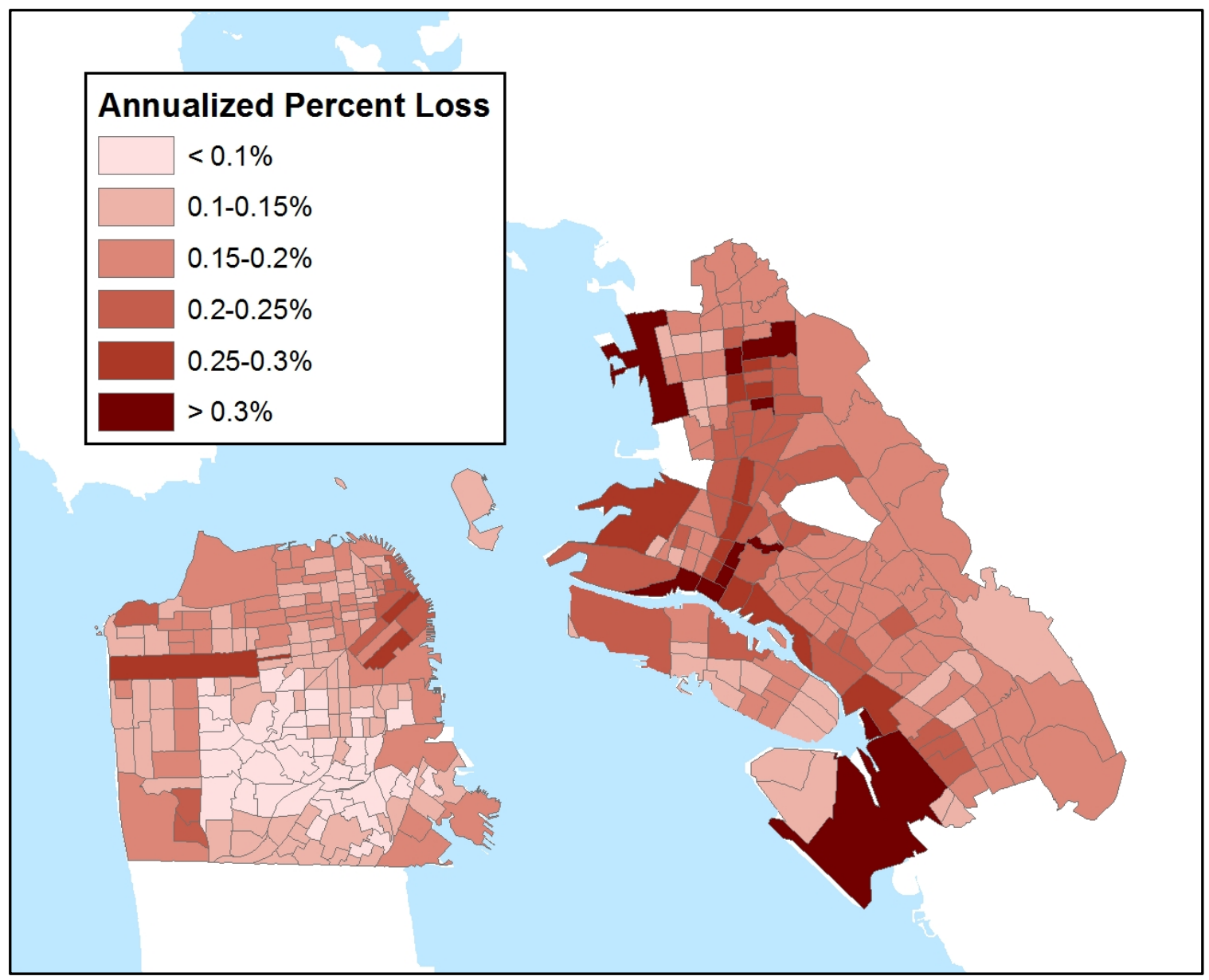

Figure 11: Annualized Percent Loss of Buildings in San Francisco, Oakland, Alameda, and Berkeley. HAZUS Data from (Chen, 2011).

Each of the studied jurisdiction's CAP was adopted within the past ten years, base lining GHG inventories with a year in the past decade. These inventories did not use the LCA method and only consider transportation, energy use, and waste emission sources. Oakland did have additional add-on emission sectors, but to be consistent with the other CAPs these emissions were omitted. With these baseline emission inventories the share of earthquakes as a portion of the overall annual emission inventory was then calculated. Table 11 highlights the roughly $1 \%$ share of emissions that earthquakes represent for four 
different jurisdictions. This is only considering structural damage; building contents and infrastructure damage would increase the GHG share further. Additionally, using HAZUS to run multiple hazards would likely increase the share of hazards. Fires, flooding and other hazards may represent greater shares for areas more prone to these disasters. Fires and floods represent repetitive natural hazards for the Bay Area but also represent secondary hazards following earthquake. Including this risk accurately could grow the emissions of hazard events significantly.

Table 11: Annualized Earthquake Hazard Emissions

\begin{tabular}{lrrrr}
\multicolumn{1}{c}{ Jurisdiction } & $\begin{array}{c}\text { Annualized Bldg. } \\
\text { EQ Loss }(\$)^{\mathrm{A}}\end{array}$ & $\begin{array}{c}\text { Annualized Bldg. EQ } \\
\text { Emissions }\left(\mathrm{MT} \mathrm{CO}_{2} \mathrm{e} / \mathrm{m}^{2}\right)^{\mathrm{B}}\end{array}$ & $\begin{array}{r}\text { CAP Emission Inventory } \\
\left(\mathrm{MT} \mathrm{CO}{ }_{2} \mathrm{e} / \mathrm{m}^{2}\right)^{\mathrm{C}}\end{array}$ & $\begin{array}{r}\text { Earthquake } \\
\% \text { of Total }\end{array}$ \\
\hline City of Alameda & $11,040,944$ & 3,640 & 303,097 & $1.19 \%$ \\
City of Oakland & $71,013,151$ & 23,360 & $2,941,165$ & $0.79 \%$ \\
City of Berkeley & $24,335,966$ & 8,000 & 576,000 & $1.37 \%$ \\
City of San Francisco & $122,582,698$ & 40,400 & $9,700,000$ & $0.41 \%$ \\
\hline
\end{tabular}

${ }^{A}$ California Geologic Survey (Chen, Wills, 2011)

${ }^{B}$ Carnegie Mellon University Green Design Institute (2013)

${ }^{c}$ City Climate Action Plans

This methodology can be very easily replicated. The Carnegie Mellon EIO calculator is user friendly, and the California Geological Survey produces annualized earthquake loss estimates for the state, breaking down annualized earthquake loss by census district (Appendix C). These two resources can be used in local, county, and state plans to calculate seismic loss contributions to emission inventories.

Prior to including disasters in CAP inventories, two areas need to be considered more closely. First, having a more accurate breakdown of the building types will provide a more accurate annualized earthquake GHG estimate. The HAZUS data is especially specific breaking down building losses into 33 building categories, 12 of which are types 
of residential housing. Expanding the LCA inventories to reflect this level of breakdown allows this refined level of building inventory to be utilized. Second, it needs to be clear what is and is not being measured in the inventory, as there is potential for double counting to occur. These issues are explored in the next section.

\section{Double Counting Emissions}

Currently Climate Action Plans quantify the greenhouse gas emissions by collecting the amount of energy (electricity, natural gas) used in a jurisdiction and the number of vehicle miles traveled. Including the proposed methodology has the potential to double count emissions in two separate ways: (1) counting emission accounted for in other jurisdictions climate action plans; and (2) counting the transportation and electrical use during the constructing phase. This section will address both double counting concerns and ways of limiting their significance.

Currently, all CAPs inventory the emissions that occur inside their boundaries. Cities with heavy industry are likely to have larger emissions, while bedroom communities are likely to have much fewer. For the most part methodologies that break up emissions by geography are easier to quantify however there are some difficulties in things like air travel or cross jurisdictional trips. The LCA method ignores these boundaries and measures the emissions of a resource and makes the user responsible for those emissions. For example, City A includes the energy needed to run a plastic bag facility inside the jurisdiction in its CAP. If the plastic bags are then used in City B only the emissions to 
transport the bags is counted for City B's CAP. This model works in the sense that City A can implement a program to make manufacturing facilities more efficient through an incentive program, something City B is not capable of. However, because City B does not measure the emissions of the resources it consumes there is no CAP incentive to reduce the use of plastic bags. In the LCA model City B would measure the emissions of plastic bags and include it in its inventory. Then a plastic bag ban or canvas bag handout campaign could be considered a GHG reduction strategy for City B. If City A and City B both count the emissions used to produce the bags then the emissions have been double counted, once in City A and once in City B. Interestingly, although they are counting the same emissions, completely different reduction strategies are available to each City. Double counting across jurisdictions proposes consistency issues and is an issue to weigh and make clear when using LCA.

Double counting can also occur within jurisdictions when LCA is included with a jurisdictions overall electricity use and transportation. If a city would like to include the emissions of building construction simply completing an LCA of that process would result in double counting of electricity and vehicle emissions. The embodied energy of buildings measured with LCA considers the energy to manufacture materials used during construction, as well as the vehicle miles traveled and electricity used to construct the building on the site. These later emissions are already included in an existing inventory, likely double counting the energy used at a construction site, or the miles traveled by the construction industry. Climate Action Plans inventory by energy draws, while the LCA inventories by processes. This can be avoided if those elements are removed from LCAs. 
This requires individual studies prepared for the CAP, or well documented past studies that are clear where emissions are generated.

Two of the studies used to generate the $\mathrm{kg} \mathrm{CO} / \mathrm{m}^{2}$ value had tables that broke down their construction phase emissions. The first was the Junnila and Horvath study (2003) of a large office building, originally described in Table 1 . The total emissions of the office building studied was 47,560 MTCO2e, 6,060 of which were included in the embedded phase, comprising building materials, construction, and demolition. The potential for double counting primarily comes from the energy used during construction and demolition. In the Junnila and Horvath study the construction phase was broken down further and is shown in Table 12.

Table 12: Breakdown of Construction Phase Emissions of an Office Building.

\begin{tabular}{lcc} 
Emission Source & $\mathrm{MT} \mathrm{CO}_{2} \mathrm{e}$ & $\begin{array}{c}\text { Double } \\
\text { Counted }\end{array}$ \\
\hline Equipment & 360 & YES \\
Electricity & 170 & YES \\
Heat & 82 & YES \\
Transportation of Building Materials & 32 & MAYBE \\
Other & 18 & MAYBE \\
Materials in Construction & 160 & NO \\
\hline \hline Construction Phase Total & 822 & - \\
\hline
\end{tabular}

Raw Data Source: Junnila \& Horvath (2003).

The only source not potentially double counted during construction is the materials in construction. This is different than building materials as these materials are not part of the actual structure, but are the form-work and scaffolding used during the construction phase. The construction phase is broken into double counted and unmeasured portions and then reinserted into the embodied emissions portion. Assuming all demolition 
emissions are double counted, Table 13 shows that roughly $80 \%$ of the embodied emissions are uncounted by standard CAP emission inventories.

Table 13: Embodied Emission Breakdown of an Office Building.

\begin{tabular}{lrr} 
Emission Source & Tons $\mathrm{CO}_{2} \mathrm{e}$ & Percentage \\
\hline Building Materials & 4,800 & $79.2 \%$ \\
Construction (Materials) & 160 & $2.6 \%$ \\
Construction (Double Counted Portion) & 662 & $10.9 \%$ \\
Demolition & 440 & $7.3 \%$ \\
\hline \hline Uninventoried Emissions & 4,960 & $81.8 \%$ \\
Inventoried Emissions & 1,102 & $18.2 \%$ \\
\hline
\end{tabular}

Raw Data Source: Junnila \& Horvath (2003).

The Fay study (2000) was chosen to compare these results. This time the case was for a single family home. Table 14 shows the building material and construction phases only, and does not have the demolition phase. The building material and construction phase ratio is similar to the Junnila and Horvath study. When incorporating the embodied emissions of structures into a standard CAP it can be assumed that the double counting represents about $10-20 \%$ of overall embodied emissions. The double counting is from the local transportation of materials and energy used onsite during the construction and demolition phase. This represents a conservative estimate as it is unclear the extent to which some categories are double counted.

Table 14: Embodied Emission Breakdown of a Single Family Home.

\begin{tabular}{lrr} 
Emission Source & Tons $\mathrm{CO}_{2} \mathrm{e}$ & Percentage \\
\hline Materials (Univentoried Emissions) & 103 & $93.3 \%$ \\
Direct Energy (Double Counted Portion) & 7 & $6.7 \%$ \\
\hline \hline Total & 110 & \\
\hline
\end{tabular}

Raw Data Source: Fay, Treloar \& Iyer-Raniga (2010). 
This scenario only considers the inclusion of building construction under normal conditions. What makes the issue of double counting more difficult and less clear is when we consider the methodology proposed in this study to include the construction following a disaster which represents a spike compared to normal conditions. In this case double counting within the jurisdiction may not occur in the projection of future emissions, but would be double counting when measuring real time, or analyzing after the event.

Both instances of double counting pose consistency issues, and decrease the transparency/understandability of CAP inventories. Currently, double counting, if well labeled does not pose a significant problem. Emission inventories simply provide a baseline to measure against. If the same methodology is used to measure again, progress is measured. In the future however, if CAPs become required, or if they are aggregated together, the double counting issues may become more difficult to accept.

Combining the two methodologies in a single plan produces an imperfect inventory that also influences how reduction strategies are chosen. It is best if a single methodology is used for the entire Climate Action Plan, but the limited amount of data prevents a complete life cycle analysis. Some researchers have attempted to quantify the urban metabolism of cities, but these processes remain incomplete or theoretical, with many assumptions due to gaps in data.

The proposed methodology offers another piecemeal portion of a city's emissions. In this analysis we include only the greenhouse gas emissions to rebuild structures after an earthquake. Not included are the regular year emissions of construction materials, nor 
the building contents damaged in earthquakes. Despite the imperfect inclusion of disaster GHG losses of buildings in inventories they can be considered properly such that double counting is a limited issue, well documented, or this might argue for a different section within a CAP to house this data. The LCA methodology also opens up new opportunities for appropriate reduction strategies that previously were disconnected to decreasing a community's greenhouse gas reduction. 


\section{CHAPTER 5}

\section{Greenhouse Gas Reduction Strategies}

The benefit of inventorying baseline emissions is the ability to then draft and implement reduction strategies to decrease greenhouse gases and losses. There are two intuitive ways in which greenhouse gas emissions can be reduced with hazard mitigation. The first method is to increase the robustness of structures to withstand hazard forces; the second is to decrease the probability of the structure's exposure to a hazard. This can be accomplished by either large infrastructure projects, or regulating land uses in areas of severe hazards.

\section{Increase Robustness}

There are conventional architectural and engineering methods that improve the ability of structures to resist forces. Each hazard is measured by unique forces (acceleration, wind speed, water depth, temperature, etc.) and structures can be designed/retrofitted to withstand them. In the case of seismic hazards, dozens of structural systems can be employed to drastically improve building performance in earthquakes. For structures in hurricane zones choosing the appropriate roofing tie can improve the performance of the entire structure in hurricane force winds. In areas prone to fires the roof shingles used are a large indicator of the fireproofing of the structure. For each hazard the concept is the same. By making resilience-enhancing choices during construction or retrofit of structures, building fragility is lessened; see Figure 12. There is still risk, but it is 
substantially less for likely, forecast events. A few example reduction strategies are included.

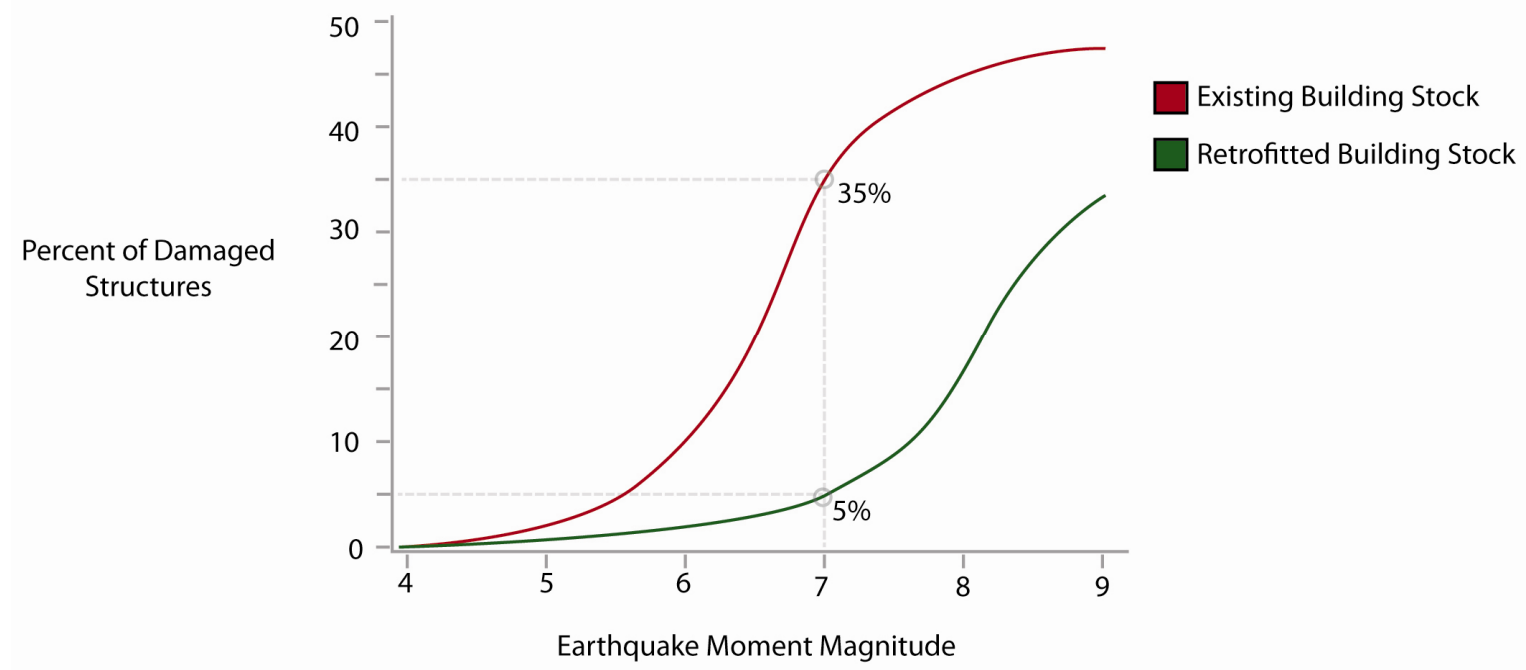

Figure 12: Theoretical impact of a building code or retrofit program on a building fragility curve.

\section{Building Code}

All future structures are built to a minimum level to ensure an improved performance during the design level hazard events. It is important to understand the results of building to this level of design. The current seismic design code simply requires buildings to not collapse, and significant damage is acceptable. The code is designed to prevent life loss in earthquakes, but can still result in the need for substantial repairs or demolition of the structure after the event. Choosing to build to a higher initial safety level will limit the loss of materials after an event. Depending on what portion of the building code is improved will determine the impact of GHG reduction. For example, if a structural code is changed it may reduce collapse damage of the entire structure. If nonstructural codes are changed to limit HVAC or mechanical system failures it further 
decreases the amount of material needing replacement after an event. In both cases GHG emissions are avoided, but preventing collapse has a greater impact on the amount of GHG emissions avoided for vulnerable structures.

Take as an example building code adoptions in Florida following Hurricane Andrew. New structures are required to have shutters or impact-resistant glass. The design wind level has steadily risen, in some areas from 140 to $160 \mathrm{mph}$, and others from 120 to 150 mph (Simmons, 2012). In recent hurricanes the performance of residential structures preand post-shingle code changes shows measureable improvements. Homes constructed prior to the code all had shingle loss of at least $10 \%$, with the majority between $25-50 \%$ shingle loss; conversely, $30 \%$ of the homes constructed with the new code had no damage, and another 55\% had less than 5\% shingle loss (Gurley et al., 2006). Using data like this, a community can measure the impact of code changes and potentially adopt standard improvements based on a desired GHG reduction goal.

\section{Retrofit Program}

There are a number of structures that are more vulnerable than others in disaster events; and past practice mostly addressed life safety issues. A number of different building characteristics can be used to narrow programs to especially vulnerable structures. The age (proxy for code used as well as general condition), construction method, and architecture of a building are all indicators of the expected performance. For some structures, retrofit may be expensive and may also yield a large amount of emissions; however, a number of relatively cheap retrofits can drastically improve the performance 
of vulnerable structures, reducing the number of destroyed and heavily damaged units after hazard events.

The City of San Francisco recently passed a mandatory residential building retrofit ordinance requiring property owners to retrofit their soft-story buildings that are a collapse risk in earthquakes (Ordinance No. 66-13). While the support for the ordinance was to improve life safety concerns and ease the need for emergency housing after earthquakes, this ordinance will also likely result in fewer greenhouse gas emissions. If structures are retrofit to a level that exceeds life safety performance so that the building will be undamaged or repairable, the emissions generated to retrofit the structure will far outweigh the emissions had the structure needed replacement. The emission reduction could be measured in theory with the following equation:

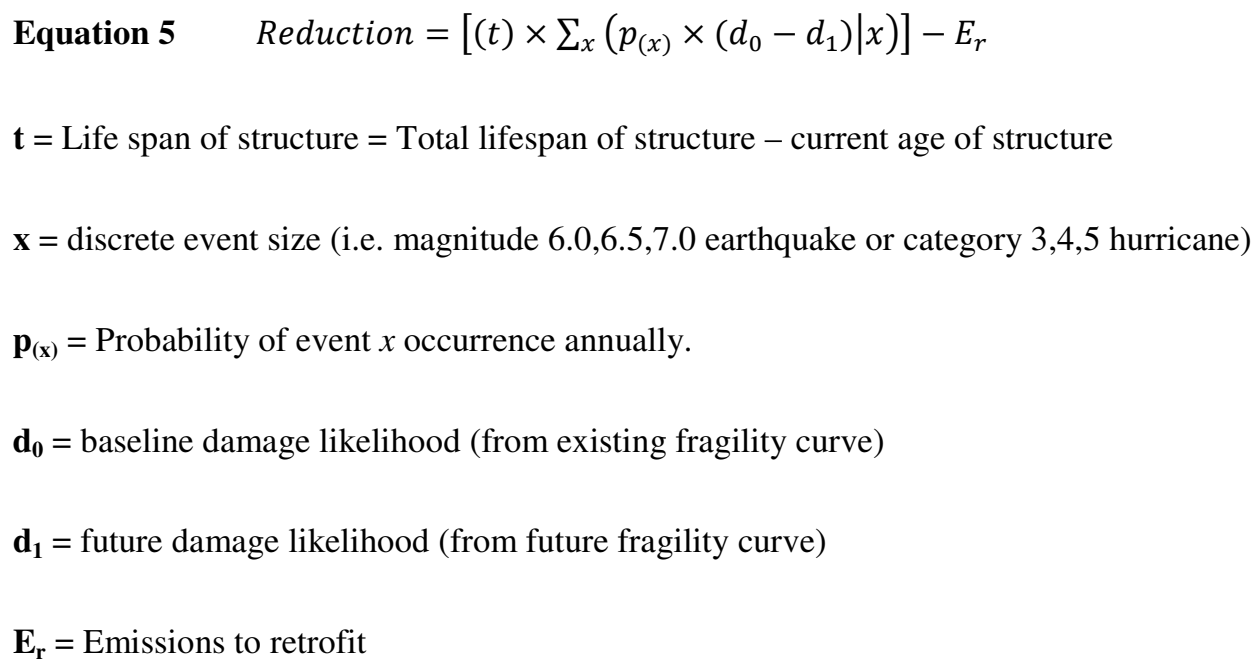

This introduces an important relationship with most retrofit projects. The emission reduction is greater when the structure has a large percentage of its building life remaining. In communities that have experienced large growth recently, emission reductions will be greater due to retrofits compared with older structures near the end of 
their life. Retrofit is an option for older structures, but when demolition and rebuild are likely, a code change (Section 5.1) to ensure the new structure is built better may be more effective. Using basic equations like the one above may help policy makers determine which method is most appropriate for their community based on local building characteristics. Additionally, to make the equation more user friendly tables could be generated to show the emission savings with a variety of different structure ages and retrofit strategies.

\section{Decrease Susceptibility}

If structures are placed outside of severe hazard zones then they are less likely to be damaged by a particular hazard compared to those in high hazard areas. This is most intuitive for flood plains which are often mapped. If a structure is built in a flood plain it is at risk of damage during a flood event, while a structure outside of the zone has less risk. 100 year and 500 year flood zones are mapped across the United States and can be used to restrict growth. The same process can restrict development in other high hazard places, but it is more difficult for less discrete and more spatially distributed forces. For some hazards, like hurricanes and earthquakes, the forces can be strong across entire regions. The wind speed may not decrease drastically across a region, and shaking may be strong at all locations in a city. For these events it's important to recognize the full suite of hazards. For hurricanes it may also be flooding due to storm surge, and for earthquakes it may be fault rupture or liquefaction that pose an increased risk above the wind or shaking severity. These hazards may be more appropriately managed with 
restrictions as they often cover a much smaller proportion of land and are more discrete making them easier to map.

\section{Land Use Hazard Overlay}

Many cities as part of their general plan process map local hazards and may restrict growth or require additional permits or review for development to occur. As mentioned the 100 year flood plain is a typical hazard overlay for many communities. In California, the Alquist Priolo Act (1972) restricts new development within fifty feet of active faults, in order to prevent fault rupture damage to structures. As a result of the 2011 and 2012 earthquakes in Christchurch, New Zealand and resulting land use and soils analysis, certain previously developed portions of the city will be converted to open space because of the very high liquefaction potential in the area (CERA.govt.nz, 2013). Placing future land uses outside of the most severe hazard zones decreases the risk exposure of the built environment. If restricting land uses is too political or too infeasible a proposal, placing additional building standards to address the higher exposure may be an appropriate middle ground that addresses both susceptibility and increased robustness solutions.

\section{Engineered Infrastructure}

For developed areas, or in areas where future development is lucrative or otherwise desirable, engineering infrastructure is a popular solution to reduce physical risk. Levees, 
reservoirs, sea walls, and fire breaks are all examples of using protective infrastructure to prevent hazards. These solutions can be a double edged sword. By engineering a structure to protect development there is then an attraction to develop in that location. Should that infrastructure ever fail or be insufficient to resist high hazard levels then the development will be further exposed. When engineered infrastructure such as levees and sea walls work, they are very effective; when they fail the results can be catastrophic. The levee failure following Hurricane Katrina is the most dramatic example of this kind of failure. These types of GHG reduction strategies can be measured by simply providing a new probability of occurrence relationships with magnitudes as seen in Figure 13. Similarly if the engineered infrastructure feature removes all risk for small events the summation used in the equation is reduced to a smaller range. Using the relationship in the figure below, $\mathrm{z}$ in Equation 3 is only calculated from 7 to 9 rather than from 4 to 9 .

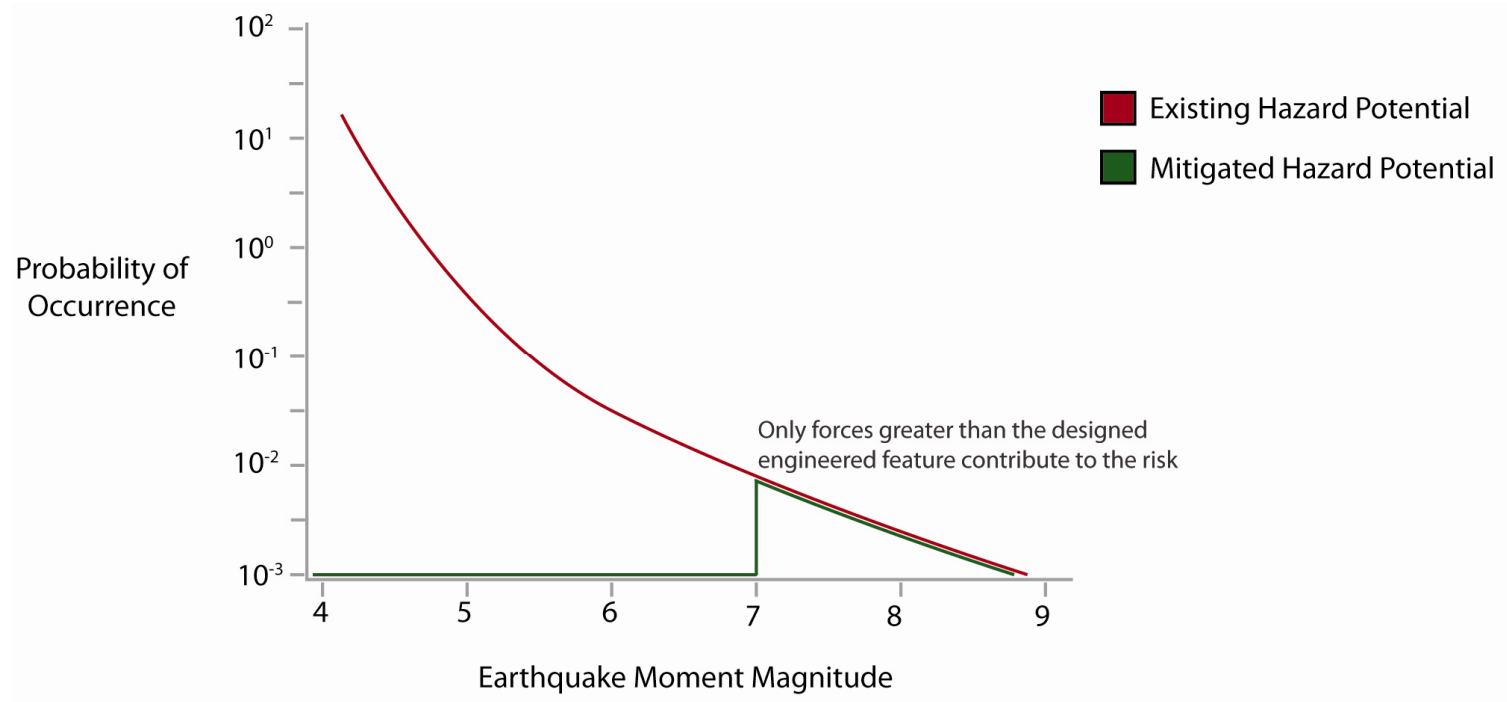

Figure 13: Impact of reduction strategy on the annual probability of hazard occurrence. 


\section{Other Reduction Strategies, Resilience Strategies}

These reduction strategies are focused specifically on structures. Other reduction strategies to reduce the damage to building contents exist. These solutions may be the most attractive for those primarily concerned with emissions because the initial emission investment to make something more robust may be very small. For example securing a television or a cabinet to a wall may only require longer screws than were used or a small piece of bracketing hardware. Additionally, typical CAP reduction strategies can also be argued as hazard mitigation strategies with small tweaks, or as is.

Many Climate Action Plans promote distributed photovoltaic arrays because of the zero emission energy they generate. Beyond the greenhouse gas benefits of the arrays, having distributed power after an event can be extremely valuable to a community. Often infrastructure systems like power are disrupted by large events and even small amounts of electricity to power emergency operations can be invaluable; however most PV systems are connected to the grid and are set up to shut down when there are outages so repair crews can work in a safe environment. Setting up an appropriate protocol to switch to an independent system would have huge benefits for response and recovery after an event. Thinking about hazards and climate change simultaneously is a significant benefit for cities to include such an addition as part of a standard CAP strategy, along with development of energy assurance plans (recently piloted in 50 California cities).

There are a number of other mutually beneficial strategies. Some smart growth planning principles benefit both greenhouse gas reduction and a city's ability to recover following disasters. Having policies to decrease the distance from home and work increase cycling 
and pedestrian modes of transportation which are less likely to be affected compared with systems that rely on roads. Prioritizing mixed use, affordable housing, and pedestrian and cycling infrastructure all decrease the reliance on vehicular transportation which can be interrupted by damaged roads, or by energy and fuel disruptions.

This thesis has examined the emission reductions of preventing the rebuild efforts following a disaster. Despite the improvements made large events will require significant amounts of rebuilding. There is often a push after disaster to build back better to reduce the hazard risk by updating the building code or restricting land uses. This is also an opportunity to rebuild destroyed standard structures as energy efficient ones. Figure 4 highlighted the difference in life cycle emissions with energy efficient homes. Replacing typical homes with energy efficient ones following an event could result in a net GHG benefit despite the large loss due to embodied emissions. These energy upgrades often come at an increased cost which may not be a possible investment following a disaster when many may not have the funds to rebuild to the most basic levels. Post disaster rebuilding may provide an opportunity to tap into cap and trade monies to rebuild structures in a manner that reduces future hazard risk, reduces future use phase emissions, and finances recovery. There are also monies provided by the Stafford Act authority to mitigate future hazards - an allocation of $15 \%$ of the public assistance funds going to a disaster region are available for improved rebuilding. Blending Stafford Act funding with potential money from a program like CAP in trade could result in a program with billions to spend on making the next generation of buildings more hazard resilient and sustainable. The post disaster environment is unique because funding for rebuilding is a 
premium and the charts in Figure 4 show that if emission reductions are desired, building an energy efficient home from the start can cut emissions in half compared to standard construction. It is an opportunity where both fields can work together to accomplish their own goals. 


\section{CHAPTER 6}

\section{Conclusions}

Cities are already benchmarking emissions and hazard losses and are attempting to decrease both through separate strategies. Blending these data sets may introduce new possibilities for strategies to benefit both causes. In a time when budgets are tight, both the environmental and hazards fields have had difficulty finding funding for mitigation strategies. Merging the multiple benefits of mitigation to highlight the benefits beyond direct impacts may create greater support for investment. Individuals concerned with climate change may be more supportive of disaster mitigation if they understand how it decreases future GHGs. The same is true for housing or economic advocates. Explaining the full suite of problems addressed with hazard mitigation may increase support enough to fund strategies that will decrease GHGs, decrease insurance costs, improve business continuity, and of course decrease life and property loss in future events.

Natural disasters exacerbated by climate change conditions form a feedback loop with dire outcomes that will continue to worsen without intervention. Larger, more disastrous events caused by climate change will result in large emissions, producing even greater potential for hazards. Hazard mitigation strategies prevent the damaging consequences of this feedback loop. Many jurisdictions have recognized that climate change will impact their community. An increasing number of CAPs are including an adaptation element, or are being drafted alongside an Adaptation Plan which offers a 
natural link between the climate change and natural hazards' risks; this innovation could provide the impetus for simultaneous hazard and GHG mitigation.

The methodology explored in this thesis provides an initial process of quantifying the greenhouse gas emissions as a result of reconstruction after a disruptive and damaging event. Single acute events result in large emissions to rebuild; but, when annualized and compared with day-to-day emissions they represent a very small amount. For the Bay Area, a region with high earthquake risk, the annualized emissions due to earthquakes was roughly $1 \%$. If a complete life cycle assessment were used for the actual emissions of the city the share would fall below $1 \%$. Considering all the unmeasured factors that make the share greater or less, the current share of earthquake-related emissions for the studied jurisdictions is likely to be about $1 \%$.

The number may seem insignificant compared to the emissions of a transportation sector, but it could be an increasingly larger share if hazards become greater and more frequent, or if communities' overall emissions inventories decrease due to changes in transportation and building efficiency.

The life cycle assessment methodology poses a number of potential hiccups in the current emission inventory process however it offers a more comprehensive overview of a jurisdiction's emissions. By measuring emission with LCA a different set of reduction strategies are available that are well connected to local government control. While the changes may not result in fewer emissions locally, it will be responsible for fewer emissions globally, which is the metric that matters most. 
There are a number of opportunities for collaborative work between the climate action and hazard mitigation communities. If their plans remain separate rather than combined either in a general plan or resilience planning document then the advocates must communicate opportunities to incorporate the others' views. A hazard mitigation strategy may focus specifically on lowering vulnerability but it should also consider if there is an easy method to incorporate greenhouse gas reduction. The same is true for greenhouse gas reduction to consider a hazards perspective.

This thesis has discussed how hazard mitigation could be quantified in greenhouse gas reduction for use in Climate Action Plans, but it could more generally be used as a perspective to be included in general policy decisions. Recently San Francisco passed a soft story retrofit program and political support in Los Angeles to address seismic safety in pre-1970 concrete buildings is growing. These issues are focusing on hazard mitigation which is the greatest concern with structures that pose a life safety risk. Including information on the greenhouse gas impact could bolster support or provide an opportunity for those undergoing a retrofit to have owners include an additional energy retrofit for an incrementally feasible cost.

This methodology can be improved as the LCA and hazards communities improve their own inventories. For jurisdiction-wide assessments, the methodology provides a granular perspective and is not intended to be used for the examination of a single building retrofit. For that type of work a more extensive assessment of the building emissions and specific hazards at the site are needed. For a jurisdiction that has already completed a HAZUS assessment, the methodology could take less than fifteen 
minutes to run if the average numbers used in this thesis are used. If local data is known then sorting through and matching data to HAZUS could provide a more accurate assessment.

The methodology used provides local jurisdictions with a fast and easy way to explore the relationship between hazard mitigation and climate action. It can be used to generate support for mutually beneficial projects, and can build support behind comprehensive resilience work. Further, it allows communities to tap a wider range of fiscal supports from multi-sectoral resources while addressing the climate and hazard risks more comprehensively and addressing the climate and hazard risks more comprehensively. 


\section{BIBLIOGRAPHY}

Air Resources Board. (2013) Sustainable Communities. California Environmental Protection Agency. Retrieved On 3.10.2013; Retrieved From:

http://www.arb.ca.gov/cc/sb375/sb375.htm

Air Resources Board. (2007) California 1990 Greenhosue Gas Emissions Level and 2020 Emissions Limit. California Environmental Protection Agency. November 16, 2007. Retrieved On 3.10.2013; Retrieved From: http://www.arb.ca.gov/cc/inventory/pubs/reports/staff_report_1990_level.pdf

Alameda County. (2011). Community Climate Action Plan. Retrieved On: 3.5.2013; Retrieved From:

http://www.acgov.org/cda/planning/documents/Community_Climate_Action_Pla n_June_2011.pdf

Benicia. (2008). Climate Action Plan. City of Benicia. September 2008.

Blanchard, S., Reppe, P., (1998). Life Cycle Analysis of a Residential Home in Michigan. Center for Sustainable Systems. University of Michigan. Report No 1998-5.

Boswell, M., Greve, A. (2012). Climate Action Plan Database, California Polytechnic State University, San Luis Obispo.

California Geological Survey Rowshandel, Reichle, Wills, Cao, Persent, Branum, Davis. (2003). Estimation of Future Earthquake Losses in California. Retrieved On 3.5.2012; Retrieved From: ftp://ftp.consrv.ca.gov/pub/dmg/rgmp/CA-LossPaper.pdf

Carnegie Mellon University Green Design Institute. (2013). Economic InputOutput Life Cycle Assessment (EIO-LCA) US 2002 (428) model Retrieved On: 3.7.2012; Retrieved from: http://www.eiolca.net/

CERA.govt.nz. (2013). Land Zones. Canterbury Earthquake Recovery Authority. Retrieved On: 1/22/2014; Retrived from: http://cera.govt.nz/landinformation/land-zones

Chen, R., Wills, C., (2011). HAZUS Annualized Earthquake Loss Estimation for California. California Geological Survey. April 2011; Retrieved From: http://www.consrv.ca.gov/cgs/rghm/loss/Pages/2010_analysis.aspx

Comerio, M., (1998). Disaster Hits Home. The Regents of the University of California. 
Dixit, M., Fernandez-Solis, J., Lavy, S., Culp, C. (2010). Identification of Parameters for embodied Energy Measurement: A Literature Review. Energy and Buildings. 42, 1238-1247.

EPA. (2013). Greenhouse Gas Equivalencies Calculator. U.S. Environmental Protection Agency. Retrieved From: http://www.epa.gov/cleanenergy/energyresources/calculator.html\#results

Fay, R., Treloar, G., Iyer-Raniga, U. (2000) Life Cycle Energy Analysis of Buildings: A Case Study. Building Research \& Information, 28:1, 31-41.

FEMA, (2013). Multi-Hazard Mitigation Plan Status. Retrieved On: 3.5.2013; Retrieved From: http://www.fema.gov/multi-hazard-mitigation-plan-status

FEMA. (2009). Hazard Mitigation Assistance Unified Guidance: Hazard Mitigation Grant Program.

FEMA. (2012). Use of HAZUS-MH to Support Individual Assistance Program. Retrieved From: http://www.fema.gov/hazus/use-hazus-multi-hazard-supportindividual-assistance-program

Gurley, K., Davis, R., Ferrera, S., Burton, J., Masters, F., Reinhold, T., Abdullah, M. (2006). Post 2004 Hurricane Field Survey - an Evaluation of the Relative Performance of the Standard Building Code and the Florida Building Code and the Florida Building Code. American Society of Civil Engineers. Structures Congress 2006. October 2006, 1-10.

Hammond, G., Jones, C. (2008). Embodied Energy and Carbon in Construction Materials. Institution of Civil Engineers. Energy. 161 EN2, 87-98.

Hamilton, C. (2010). Requiem for a Species: Why We Resist the Truth About Climate Change. London, Earthscan.

Hillman, T., Ramaswami, A. (2010) Greenhouse Gas Emission Footprints and Energy Benchmarks for Eight U.S. Cities. American Chemical Society. Environmental Science and Technology. Vol. 44, No. 6, 2010.

Hsu, S. (2009). Life Cycle Assessment of Materials and Construction in Commercial Structures: Variability and Limitations. Massachusetts Institute of Technology. Retrieved from: http://stuff.mit.edu/afs/athena/dept/cron/project/concrete-sustainabilityhub/Literature\%20Review/Building\%20Energy/Thesis/Libby\%20Hsu\%20Thesis. pdf 
Junnila, S., Horvath, A. (2003). Life-Cycle Environmental Effects of an Office Building. American Society of Civil Engineers. Journal of Infrastructure Systems. December 2003. Pgs. 157-166.

Matthews, H., Small, M. (2001). Extending the Boundaries of Life-Cycle Assessment through Environmental Economic Input-Output Models. Journal of Industrial Ecology. Vol. 4, Num. 3

Monahan, J., Powell, J., (2011). An Embodied Carbon and Energy Analysis of Modern Methods of Construction in Housing: A Case Study Using a Lifecycle Assessment Framework. Energy and Buildings. 43, 179-188.

Nassen, J., Holmberg, J., Wadeskog, A., Nyman, M. (2006). Direct and Indirect Energy Use and Carbon Emissions in the Production Phase of Buildings: An Input-Output Analysis. Energy. 32, 1593-1602.

Ordinance No. 66-13 (2013). Building Code - Mandatory Seismic Retrofit Program - Wood-Frame Buildings; Optional Evaluation Form Fee. City of San Francisco. Retrieved From:

http://www.sfgsa.org/modules/showdocument.aspx?documentid=10118

Poyar, K., Beller-Simms, N. (2010). Early Response to Climate Change: An Analysis of Seven U.S. State and Local Climate Adaptation Planning Initiatives. American Meteorological Society. Vol 2, 237-248.

Ramaswami, A., Hillman, T., Janson, B., Reiner, M., Thomas, G. (2008). A Demand-Centered, Hybrid Life-Cycle Methodology for City-Scale Greenhouse Gas Inventories. American Chemical Society. Environmental Science and Technology. Vol. 42, No. 17, 2008

Ramesh, T., Prakash, R., Shukla, K. (2010). Life Cycle Energy Analysis of Buildings: An Overview. Energy and Buildings. 42, 1592-1600.

San Francisco. (2004). Climate Action Plan For San Francisco. San Francisco Department of the Environment \& San Francisco Public Utilities Commission. September 2004.

Sharrard, A., Matthews, S., Ries, R. (2008). Estimating Construction Project Environmental Effects Using Input-Output-Based Hybrid Life-Cycle Assessment Model. Journal of Infrastructure Systems. ASCE. 2008, 14:4 327-336.

Simmons, J., (2012). Hurricane Andrew: 20 years later, Florida Building Code "really made a difference". ABC News. Retrieved On: 11/14/2013. Retrieved From: http://www.abcactionnews.com/dpp/news/state/hurricane-andrew-20years-later-florida-building-code-really-made-a-difference 
Simonen, K., Haselbach, L., (2012) Life Cycle Assessment and Building Research for WA State. University of Washington and Washington State University. Final Report Aug 31, 2012.

TIAX LLC. (2007). Full Fuel Cycle Assessment Tank to Wheels Emissions and Energy Consumption. Consultant Prepared for California Energy Commission, CEC-600-2007-003-D Pg.14, Retrieved on 2.5.2013, Retrieved from: http://www.energy.ca.gov/2007publications/CEC-600-2007-003/CEC-600-2007$\underline{003-D . P D F}$

US Census. (2010). Characteristics of New Single-Family Houses. Retrieved From: http://www.census.gov/construction/chars/

US Census. (2007). Characteristics of New Multifamily Houses. Retrieved From: http://www.census.gov/construction/chars/

West, C., Lenze, D. (1994). Modeling the Regional Impact of Natural Disaster and Recovery: A General Framework and an Application to Hurricane Andrew. International Regional Science Review 17.2: 121-150. 


\section{APPENDIX A: FEMA's Preliminary Damage Assessment Methodology}

\section{PDA Damage State Definitions}

Destroyed - structure is a total loss or damaged to such an extent that repairs are not economically feasible. Any one of the following may constitute a status of destroyed:

- Repair of structure is not economically feasible;

- Structure is permanently uninhabitable;

- There is a complete failure of major structural components (collapse of walls or roof);

- Unaffected structure will be required to be removed or demolished due to ordinance (e.g., beachfront homes removed due to severe beach erosion).

Major - structure has sustained structural or significant damage, is uninhabitable and requires extensive repairs. Any of the following may constitute major damage:

- Substantial failures to structural elements of the residence (e.g., walls, floors, foundations);

- Damage to the structure exceeds the Disaster Housing Program, Home Repair Grant maximum $(\$ 10,000)$;

- General exterior property damage exceeds the Disaster Housing Program Home Repair Grant maximum (e.g., roads and bridges, wells, earth movement) and has more than $50 \%$ damage to the structure.

- Damage will take more than 30 days to repair.

Minor - structure is damaged and uninhabitable, but may be made habitable in a short period of time with home repairs. Any of the following may constitute minor damage:

- Structure can be repaired within 30 days;

- Structure has more than $\$ 100$ of eligible habitability items through the Disaster Housing Program, Home Repair Grant; has less than $\$ 10,000$ of eligible habitability items through the Disaster Repair Program, Home Repair Grant.

- Damage repair costs are less than $50 \%$ of total value of house.

Affected - structures sustain some damage to structure and contents but which are habitable without repairs, and damage to habitability items is less than Disaster Housing Program, Home Repair Grant minimum. 


\section{APPENDIX B: Process Based LCA Database Table}

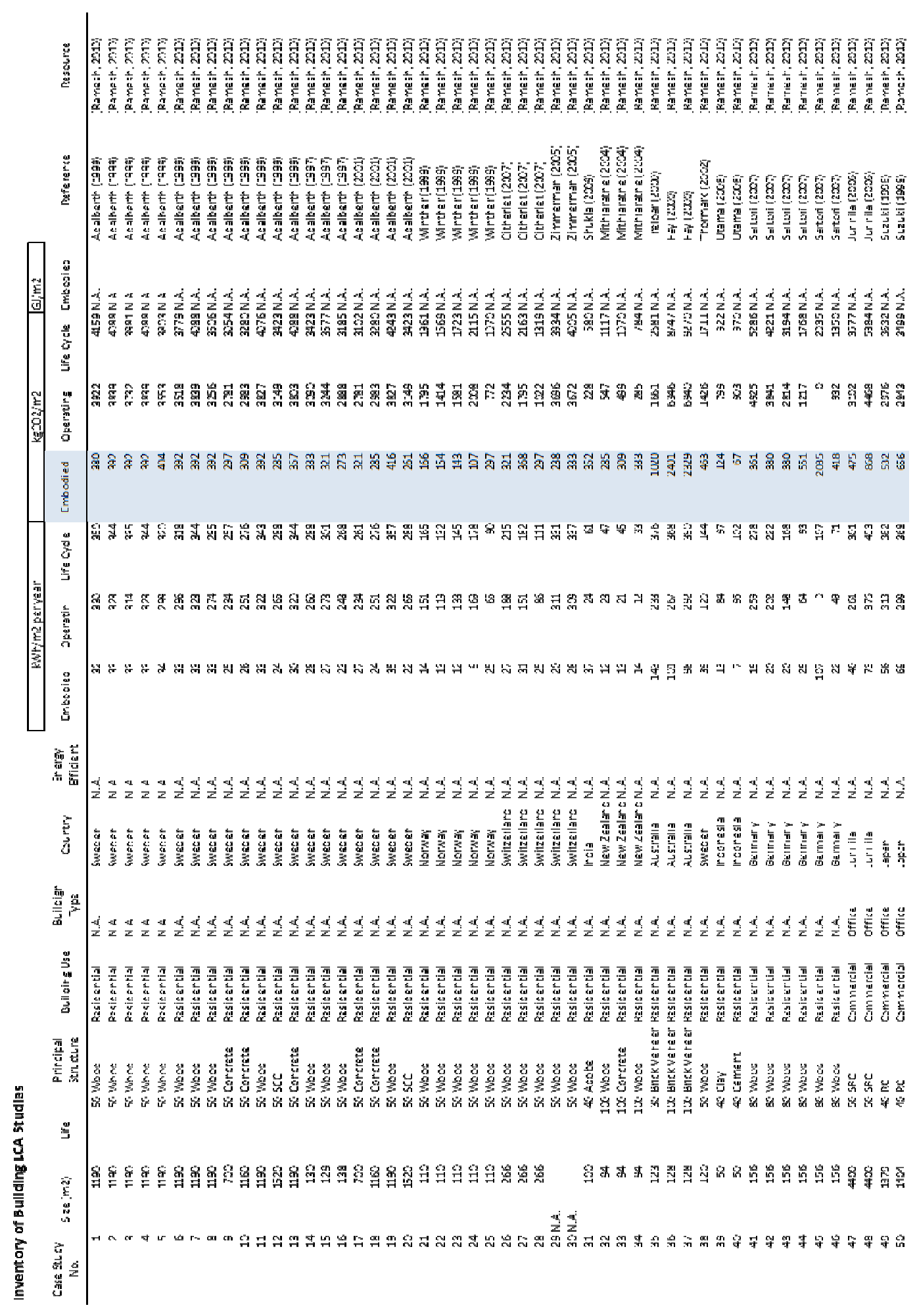

Page 67 


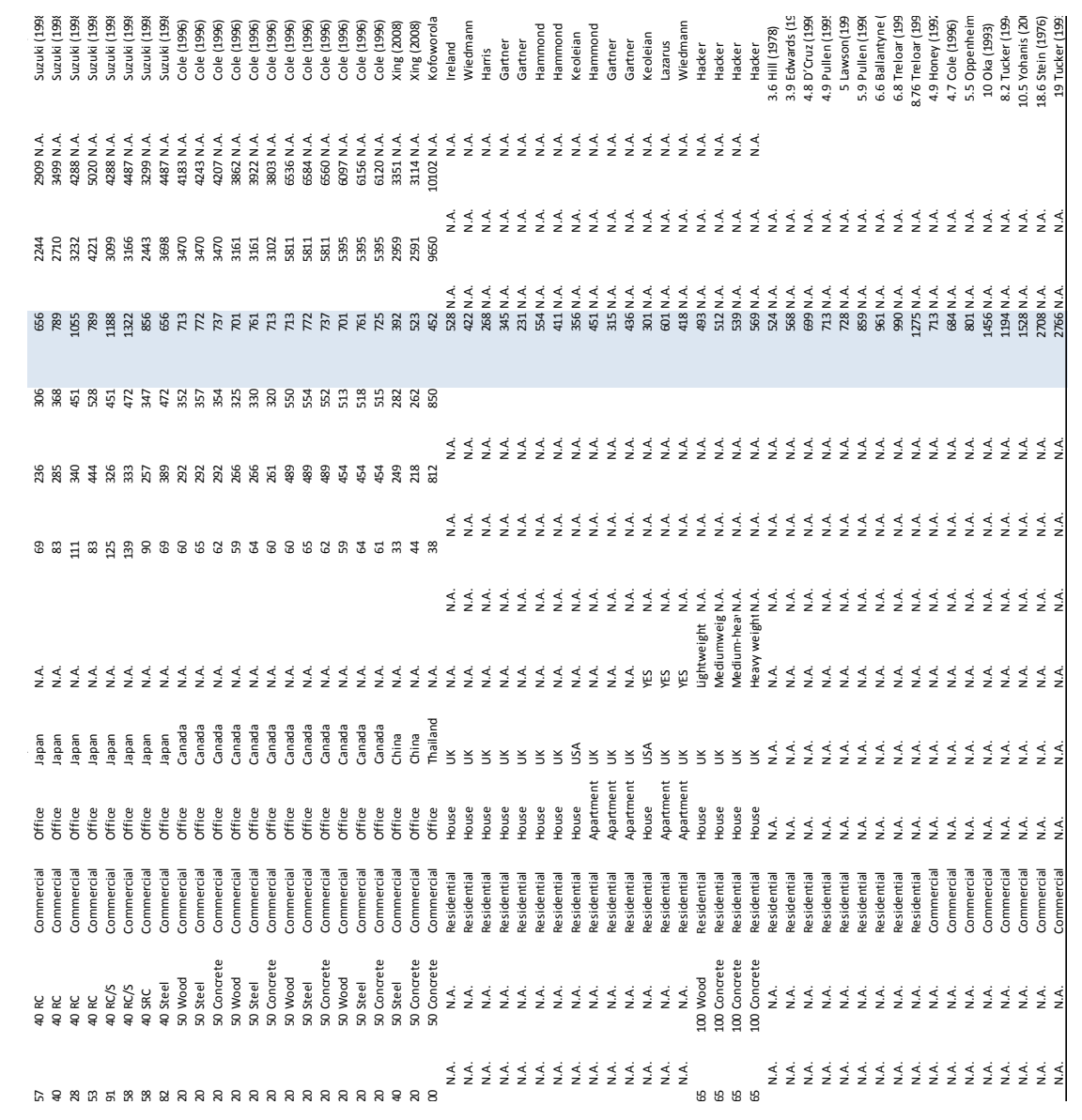

Page 68 
APPENDIX C: CGS Annualized Building Loss Assessment

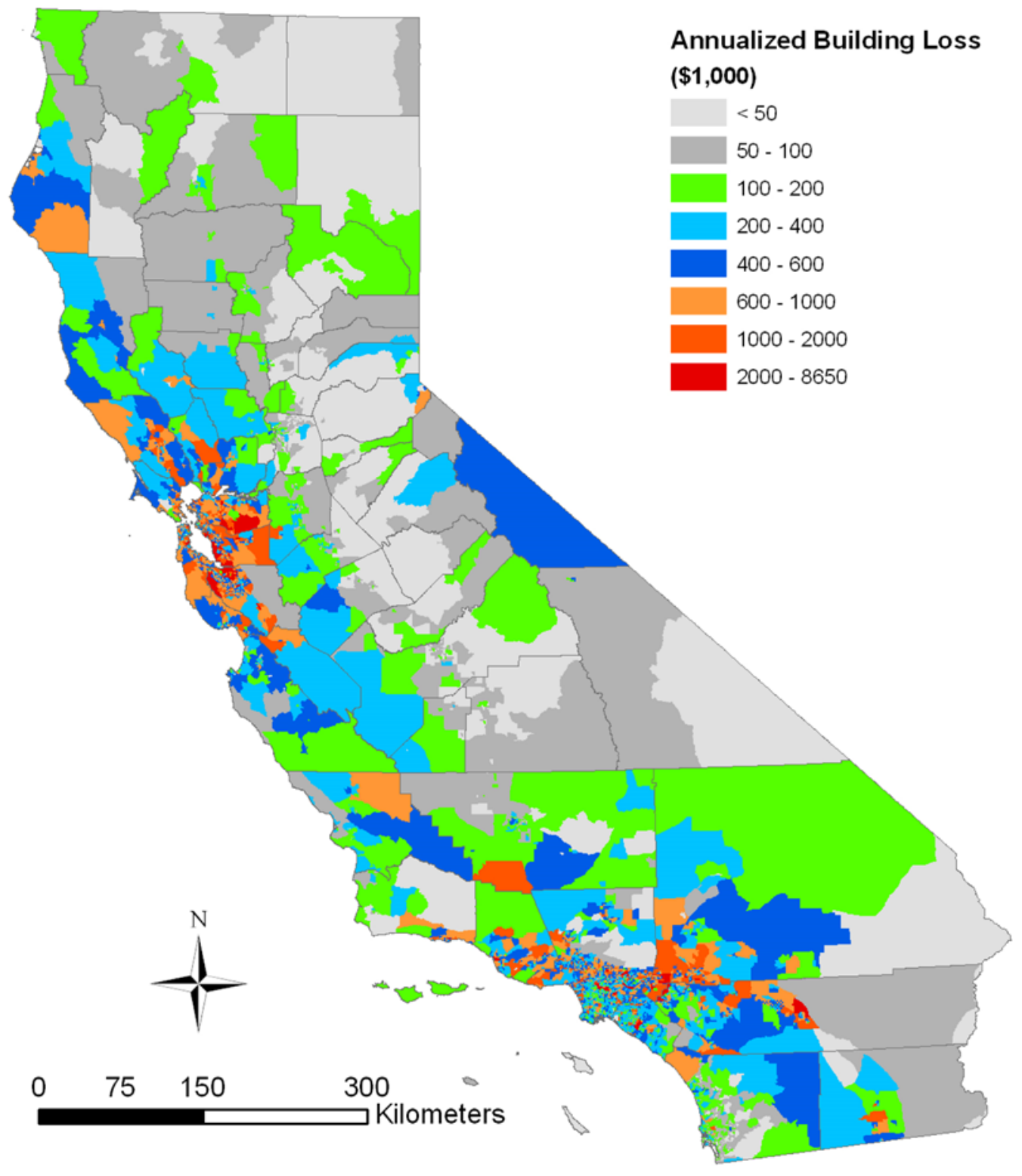

Page 69 